\title{
Post-Process Treatments on Supersonic Cold Sprayed Coatings: A Review
}

\author{
Wen Sun $1,2, * \mathbb{C}$, Adrian Wei-Yee Tan ${ }^{1,2}$, Kaiqiang Wu ${ }^{1,2}{ }^{-}$, Shuo Yin ${ }^{3} \mathbb{C}$, Xiawei Yang ${ }^{4}$, \\ Iulian Marinescu ${ }^{5}$ and Erjia Liu $2, *$ (D) \\ 1 Rolls-Royce@NTU Corporate Lab, Nanyang Technological University, 50 Nanyang Avenue, \\ Singapore 639798, Singapore; adriantan@ntu.edu.sg (A.W.-Y.T.); KAIQIANG001@e.ntu.edu.sg (K.W.) \\ 2 School of Mechanical and Aerospace Engineering, Nanyang Technological University, 50 Nanyang Avenue, \\ Singapore 639798, Singapore \\ 3 Department of Mechanical and Manufacturing Engineering, Trinity College Dublin, The University of \\ Dublin, Parsons Building, Dublin 2, Ireland; yins@tcd.ie \\ 4 State Key Laboratory of Solidification Processing, Shaanxi Key Laboratory of Friction Welding Technologies, \\ Northwestern Polytechnical University, Xi'an 710072, China; yangxiawei@nwpu.edu.cn \\ 5 Central Technology Group, Rolls-Royce Singapore Pte. Ltd., Singapore 797565, Singapore; \\ Iulian.Marinescu2@Rolls-Royce.com \\ * Correspondence: sunwen@ntu.edu.sg (W.S.); mejliu@ntu.edu.sg (E.L.)
}

Received: 6 January 2020; Accepted: 22 January 2020; Published: 1 February 2020

\begin{abstract}
Cold Gas Dynamic Spray or Supersonic Cold Spray, or simply 'Cold Spray', is an emerging technology for rapidly building thin films, thick coatings and large-scale additive manufacturing at relatively low temperatures. In a cold spray process, particles are accelerated to supersonic speeds by a propellant gas and impact a substrate, thus producing a strong bonding with the substrate and subsequently forming a deposit via layer-by-layer buildup. The scalability and low cost of this method make it promising for many applications in industry, such as metal component surface repair/enhancement/restoration and functional coatings for electrical, thermal, biomedical, energy storage, and nuclear plant applications. However, cold sprayed deposits usually require post process treatments to further modify their microstructures and mechanical properties in order to obtain the desired performances. A number of studies have been carried out on this topic. Here, recent progress in different post process treatments on cold sprayed deposits is reviewed, including heat treatment, friction-stir processing, shot peening, and laser re-melting. The effects of these post treatments on the microstructure, residual stress and mechanical properties of cold sprayed deposits are discussed.
\end{abstract}

Keywords: cold spray; metallic deposit; post-process treatment; microstructure; mechanical characteristics

\section{Introduction}

Cold Spray is a solid-state metal powder deposition technique that can be used for thin/thick coating deposition, metal surface repair and additive manufacturing, which has attracted much attention in aerospace, marine and offshore, oil and gas, power, and automotive industries [1,2]. The fundamental working principle of cold spray is that micro-sized metal particles are accelerated by a high-pressure gas to a supersonic speed via a convergent-divergent nozzle. With high kinetic energies, the metal particles deposit on the substrate surface and form a dense coating of a high adhesive strength with a low temperature input. Compared with other thermal spray means, the beauty of cold spray technology is that the metal particles retain the solid state and both the coating and substrate materials will not suffer from phase transformation, grain growth and oxidation [3,4]. Moreover, cold spray deposition is applicable to nearly unlimited materials, such as pure metals, metal alloys, polymers, 
and hybrid materials (metal-metal, metal-alloy, metal-ceramic and metal-graphene/carbon nanotube, etc.) [5-8]. Thus, cold spray technology holds great potential as a next-generation large-scale and low-cost coating/additive manufacturing technology in industry.

For the coating/substrate bonding mechanisms in cold spray, there are a number of hypotheses about this topic. One of the hypotheses proposed by Ichikawa et al. [9] is that the high velocity of a particle breaks the natural oxide film on the particle and substrate surface and the progressive plastic flow of the materials enables metallic bonding at atomic scale through direct contact between the adjacent fresh metal surfaces. Recently, there have been debates on the necessity of adiabatic shear instability (ASI) during cold spray bonding process. Assadi et al. [3] proposed that ASI plays an important role in generating bonding at the impact region where the thermal softening of the material is locally dominant over strain and strain rate hardening. The occurrence of ASI causes the viscous flow of material in an outward direction at temperatures near the melting point and thus creates a jetting [3]. However, Hassani-Gangaraj et al. [10] argued that ASI is not necessary for particle bonding based on modeling and single particle impact experiment results. Instead, they proposed that hydrodynamic jetting is formed as a result of strong pressure waves interacting with the expanding edge of the particle [10]. Moreover, mechanical interlocking [11-13], interfacial mixing [14,15], local melting [16], and diffusion [17] mechanisms also have been proposed to explain particle bonding formed during cold spray deposition. However, the topic on bonding mechanism in cold spray is still a mystery and needs further investigation.

Due to the bonding nature of cold sprayed particles, micropores within the as-sprayed coating are always inevitable, which leads to the degradation of mechanical properties of the coating and its bonding to the substrate [18]. The particle-particle interfacial strength is generally lower than the strength of the bulk material due to limited atomic diffusion among different splats during the cold spray process. In addition, the ductility of cold sprayed coatings is very limited, which may restrict their applications. Moreover, the distribution and magnitude of residual stress in the cold sprayed coating can significantly affect the coating adhesion strength and structural integrity. Residual stress induced by cold spray process can be classified into particle peening dominant and thermal mismatch dominant mechanisms [19-21]. Boruah et al. [22] recently found that high tensile residual stresses developed near the free surface of a cold sprayed Ti6Al4V coating. The presence of high tensile residual stress at the coating surface may increase the tendency of coating delamination at the coating/substrate interface and limit the maximum coating thickness that can be obtained. In order to improve the quality of cold sprayed coatings (such as adhesion strength, structural homogeneity, densification and ductility, etc.), post treatments are necessary, which have been extensively investigated by our research team and other researchers.

To date, there have been many publications regarding the effect of post-process treatments on cold sprayed coatings, but a comprehensive review on this topic is still lacking. This paper comprehensively and critically reviews different post-process treatment methods of cold sprayed coatings. Firstly, the most widely used post-process heat treatment (HT) methods will be reviewed and different heat treatment processes on different materials will be compared. Then, the focus will be directed towards the application of friction-stir processing (FSP) as a post-process treatment technique. Following that, the effects of post shot peening (SP) and laser re-melting (LR) on cold sprayed coatings will be reviewed. Furthermore, some other post-process treatments on cold sprayed coatings will be summarized, including thermo-mechanical processing, hot isostatic pressing (HIP), surface finish turning and ball-burnishing. Based on the review, suggestions and recommendations for further research directions are also provided.

\section{Heat Treatment}

Heat treatment is one of the most common methods employed for post-treatment of cold sprayed coatings, which can be achieved by furnace or laser or eddy current heating. A number of studies on this topic have been reported as summarized in Table 1. The selection of HT temperature and 
duration is usually based on the materials' properties. For instance, for $\mathrm{Al}$ and copper deposits, HT temperature is usually lower than $400{ }^{\circ} \mathrm{C}$ [23] and $700{ }^{\circ} \mathrm{C}$ [24], respectively. In contrast, for niobium deposits (melting point: $\sim 2500^{\circ} \mathrm{C}$ ), HT should be carried out at $\sim 1500^{\circ} \mathrm{C}$ to achieve good ductility and tensile strength [25]. As for HT environment, vacuum or inert gas protection rather than exposure to air is preferred to avoid oxidation as well as to yield lower coating porosity levels [24,26,27].

Huang et al. [28] reported the effects of $\mathrm{HT}$ on cold sprayed dense (Al and $\mathrm{Cu}$ ) and porous (Ti and SS316) coatings. In the as-sprayed coating, it was found that high dislocation density and some micro-sized and nano-sized grains were present, which resulted from high kinetic energy impact and severe plastic deformation. At a lower HT temperature, for relatively dense coatings, the porosity level slightly dropped [28], which was probably due to the occurrence of diffusion across the inter-particle interfaces, triggering closing of the inter-particle interfaces and tiny pores [26]. For relatively porous coatings, diffusion was not so intensive as for the dense coatings, because there existed gaps between weak-bonded particles, and thus porosity decrease was not obvious (Figure 1b) [28]. With further increasing HT temperature, more intensive diffusion resulted in further elimination of splat boundaries and the grain size became more uniform due to recrystallization (Figure 1c). With even higher HT temperature, the grains grew even larger and some defects in the cold sprayed coatings were further healed (Figure 1d). However, HT cannot fix all of the defects or pores inside the coatings, even with higher heat treatment temperatures.

(a)

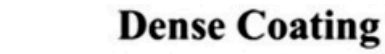

(b)
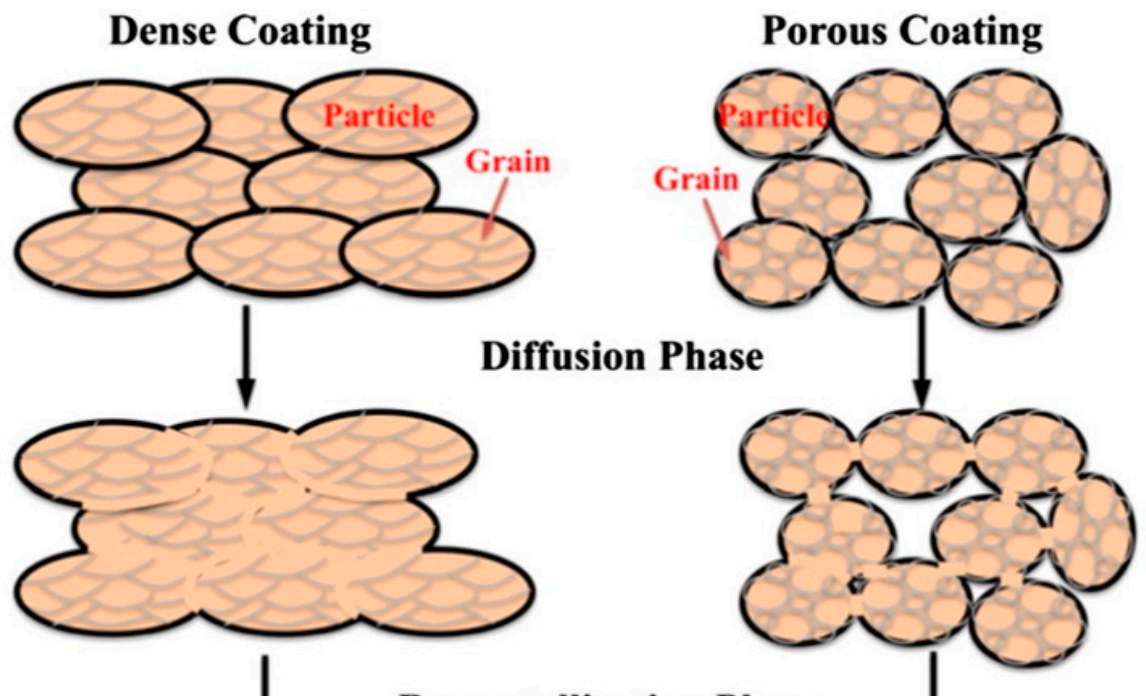

(c)

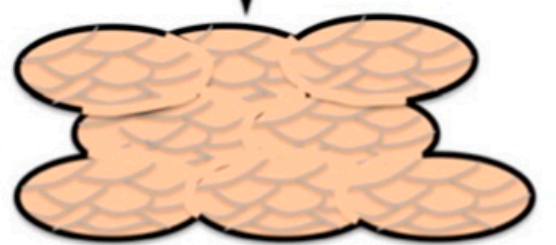

iffusion Phase

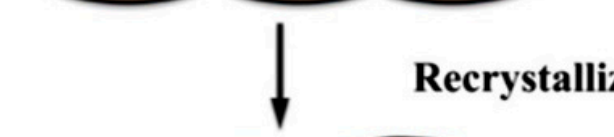

Recrystallization Phase

(d)
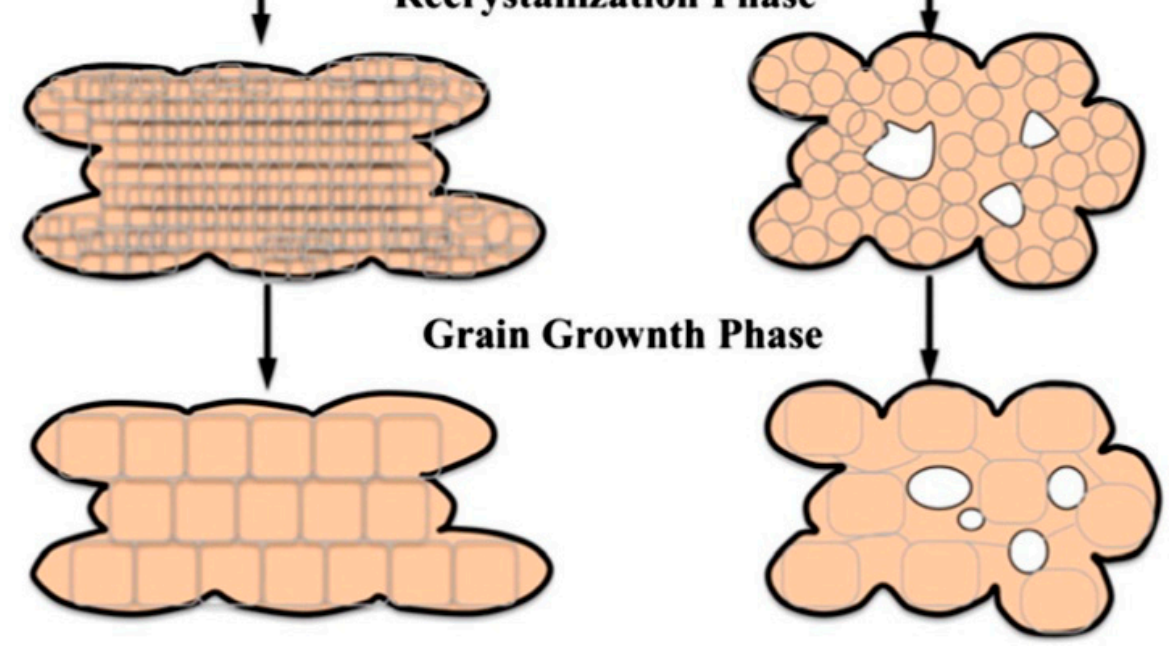

Figure 1. Microstructure evolution of cold sprayed dense and porous deposits during post HT (adapted from reference [28], with permission from ${ }^{\circledR}$ Elsevier). 
Table 1. Effect of heat treatment on cold sprayed coatings.

\begin{tabular}{|c|c|c|c|}
\hline Coatings & References & HT Parameters & Main Findings \\
\hline $\mathrm{Cu}$ & [24] & $\begin{array}{l}\text { Temperature: } 300^{\circ} \mathrm{C} \\
\text { Duration: } 1 \mathrm{~h} \\
\text { Atmosphere: vacuum, air }\end{array}$ & $\begin{array}{l}\text { The electrical conductivity of the coatings after HT was comparable to bulk } \\
\text { materials. Vacuum condition during HT yielded lower porosity and higher } \\
\text { conductivity of the coatings. }\end{array}$ \\
\hline $\mathrm{Cu}$ & [29] & $\begin{array}{l}\text { Temperature: } 300-700{ }^{\circ} \mathrm{C} \\
\text { Duration: } 3 \mathrm{~h} \\
\text { Atmosphere: } \mathrm{Ar}\end{array}$ & $\begin{array}{l}\text { The microstructural and mechanical anisotropies in the coatings were relieved } \\
\text { after HT. HT could effectively decrease the anisotropy of tensile strength. } \\
\text { While, its effect on elongation anisotropy was very limited. }\end{array}$ \\
\hline $\mathrm{Cu}-4 \mathrm{Cr}-2 \mathrm{Nb}$ & [30] & $\begin{array}{l}\text { Temperature: } 250-950{ }^{\circ} \mathrm{C} \\
\text { Duration: } 2 \mathrm{~h} \\
\text { Atmosphere: vacuum }\end{array}$ & $\begin{array}{l}\text { The microhardness of the coatings was the highest after } \mathrm{HT} \text { at } 350^{\circ} \mathrm{C} \text { due to } \\
\text { the formation of } \mathrm{Cr}_{2} \mathrm{Nb} \text { and gradually decreased with increasing } \mathrm{HT} \\
\text { temperature due to coarsening of the } \mathrm{Cr}_{2} \mathrm{Nb} \text { phase and softening of the } \mathrm{Cu} \\
\text { matrix. }\end{array}$ \\
\hline Al6061 & {$[31]$} & $\begin{array}{l}\text { Temperature: } 176^{\circ} \mathrm{C} \\
\text { Duration: } 1 \mathrm{~h}, 8 \mathrm{~h} \\
\text { Atmosphere: air }\end{array}$ & $\begin{array}{l}\text { After HT, the UTS of the coatings was improved because of the formation of } \\
\text { strengthening precipitates and the localized improvement in metallurgical } \\
\text { bonding. }\end{array}$ \\
\hline $\begin{array}{l}\mathrm{Al}-25 \mathrm{Ni} \\
\mathrm{Al}-25 \mathrm{Ti}\end{array}$ & [32] & $\begin{array}{l}\text { Temperature: } 450-630{ }^{\circ} \mathrm{C} \\
\text { Duration: } 4 \mathrm{~h} \\
\text { Atmosphere: } \mathrm{N}_{2}\end{array}$ & $\begin{array}{l}\text { Well dispersed intermetallic compounds were formed in the coatings after HT, } \\
\text { leading to increased hardness of the coatings. }\end{array}$ \\
\hline $\mathrm{Al}$ & [23] & $\begin{array}{l}\text { Temperature: } 400^{\circ} \mathrm{C} \\
\text { Duration: } 20 \mathrm{~h} \\
\text { Atmosphere: } \mathrm{Ar}\end{array}$ & $\begin{array}{l}\mathrm{An} \mathrm{Al}_{3} \mathrm{Mg}_{2} \text { or } \mathrm{Mg}_{17} \mathrm{Al}_{12} \text { intermetallic compound layer was formed at the } \\
\text { coating/substrate interface, which was significantly harder than the aged AZ91 } \\
\text { alloy and offered a corrosion resistance similar to that of the } \mathrm{Al} \text { alloys. }\end{array}$ \\
\hline $\mathrm{Fe}-40 \mathrm{Al}$ & [33] & $\begin{array}{l}\text { Temperature: } 650-1100{ }^{\circ} \mathrm{C} \\
\text { Duration: } 5 \mathrm{~h} \\
\text { Atmosphere: } \mathrm{Ar}\end{array}$ & $\begin{array}{l}\text { After HT, a Fe-Al intermetallic compound was formed within the coating, and } \\
\text { the erosion resistance of the coating increased since the erosion mechanism } \\
\text { was converted from spalling off to micro-cutting and ploughing of erosive } \\
\text { particles. }\end{array}$ \\
\hline SS316L & [26] & $\begin{array}{l}\text { Temperature: } 1000{ }^{\circ} \mathrm{C} \\
\text { Duration: } 4-8 \mathrm{~h} \\
\text { Atmosphere: Air, vacuum }\end{array}$ & $\begin{array}{l}\text { Enhanced mechanical properties of the coatings were mainly dominated by } \\
\text { improved inter-particle bonding and particle grain structure rather than } \\
\text { reduction of porosity. Air annealing only slightly improved the tensile } \\
\text { strength and ductility of the SS316L deposits. Vacuum annealing significantly } \\
\text { improved the tensile strength and ductility of the SS613L deposits. }\end{array}$ \\
\hline SS304 & [34] & $\begin{array}{l}\text { Temperature: } 600-950^{\circ} \mathrm{C} \\
\text { Duration: } 1 \mathrm{~h} \\
\text { Atmosphere: vacuum }\end{array}$ & $\begin{array}{l}\text { Annealing treatment healed up the weakly bonded interfaces and changed the } \\
\text { particle bonding mechanism from mechanical interlocking to metallurgical } \\
\text { bonding under certain annealing conditions. }\end{array}$ \\
\hline
\end{tabular}


Table 1. Cont.

\begin{tabular}{|c|c|c|c|}
\hline Coatings & References & HT Parameters & Main Findings \\
\hline $\mathrm{Ti}$ & [27] & $\begin{array}{l}\text { Temperature: } 600{ }^{\circ} \mathrm{C} \\
\text { Duration: } 1 \mathrm{~h} \\
\text { Atmosphere: vacuum, } \mathrm{Ar}, 5 \% \mathrm{H}_{2}+\mathrm{Ar}\end{array}$ & $\begin{array}{l}\text { Among the three HT environments, vacuum could promote the highest } \\
\text { hardness and the lowest porosity of the coatings. }\end{array}$ \\
\hline $\mathrm{Ti}$ & [35] & $\begin{array}{l}\text { Temperature: } 850^{\circ} \mathrm{C} \\
\text { Duration: } 4 \mathrm{~h} \\
\text { Atmosphere: } \mathrm{Ar}\end{array}$ & $\begin{array}{l}\text { Micro-CT analysis showed that the majority of the pores in the coatings after } \\
\text { HT were smaller than those in the as-sprayed coatings. }\end{array}$ \\
\hline Ti-WC & [36] & $\begin{array}{l}\text { Temperature: } 550-650{ }^{\circ} \mathrm{C} \\
\text { Duration: } 1 \mathrm{~h} \\
\text { Atmosphere: } \mathrm{Ar}\end{array}$ & $\begin{array}{l}\text { After HT, coating porosity dropped. The hardness and wear resistance of the } \\
\text { coatings increased due to the formation of TiC phase. }\end{array}$ \\
\hline IN718 & [37] & $\begin{array}{l}\text { Temperature: } 900^{\circ} \mathrm{C} \\
\text { Duration: } 10 \text { min } \\
\text { Atmosphere: vacuum }\end{array}$ & $\begin{array}{l}\text { Compared with traditional furnace HT, eddy current HT was used, which was } \\
\text { more efficient in promoting atomic diffusion and mass transport between the } \\
\text { particles in the coatings, thus leading to a higher strength of the coatings. }\end{array}$ \\
\hline IN718 & [38] & $\begin{array}{l}\text { Temperature: } 990^{\circ} \mathrm{C} \\
\text { Duration: } 4 \mathrm{~h} \\
\text { Atmosphere: } \mathrm{Ar}\end{array}$ & $\begin{array}{l}\text { A high-performance of the coatings after HT was achieved with the adhesive } \\
\text { strength between coatings and substrates being comparable with the tensile } \\
\text { strength of the bulk materials after HT. }\end{array}$ \\
\hline IN718 & [39] & $\begin{array}{l}\text { Temperature: } 950-1250{ }^{\circ} \mathrm{C} \\
\text { Duration: } 1-2 \mathrm{~h} \\
\text { Atmosphere: } 10 \% \mathrm{H}_{2}+\mathrm{Ar}\end{array}$ & $\begin{array}{l}\text { The ultimate tensile strength of the coatings after HT was about } 62 \% \text { of that of } \\
\text { the bulk materials and the elongation of the coatings exceeded that of the bulk } \\
\text { materials. }\end{array}$ \\
\hline $\mathrm{Nb}$ & [25] & $\begin{array}{l}\text { Temperature: } 500-1250{ }^{\circ} \mathrm{C} \\
\text { Duration: } 1 \mathrm{~h} \\
\text { Atmosphere: Ar }\end{array}$ & $\begin{array}{l}\text { After HT, coating porosity was eliminated, and inter-particle boundaries in the } \\
\text { coatings were closed. The elastic modulus and tensile strength of the coatings } \\
\text { were close to those of the bulk materials after HT at above } 1250{ }^{\circ} \mathrm{C} \text {. }\end{array}$ \\
\hline $\mathrm{Ni} / \mathrm{FeSiAl}$ & [40] & $\begin{array}{l}\text { Temperature: } 200-800{ }^{\circ} \mathrm{C} \\
\text { Duration: } 2 \mathrm{~h} \\
\text { Atmosphere: } \mathrm{Ar}\end{array}$ & $\begin{array}{l}\text { The soft magnetic performance of the coatings was significantly improved via } \\
\text { stress relief and grain growth after proper HT. }\end{array}$ \\
\hline
\end{tabular}


In addition, dislocation density in the coating drops and grain size becomes larger due to the occurrence of recovery in the microstructure, which has been proven by electron backscatter diffraction (EBSD) as well as transmission electron microscopy (TEM) analyses [37,38]. Figure 2 shows that Kernel Average Misorientation (KAM) values in cold sprayed Inconel 718 coatings significantly dropped after HT, which indicates a decrease of dislocation density [38]. In our previous work on HT of cold sprayed Inconel 718 coatings [37], under the observation of TEM, high-density dislocations and narrow twin bands were observed in the deformed splats due to severe plastic deformation. After HT, the dislocations reordered into cell networks and formed some recrystallized sub-grains. Apart from this, grain growth and twin-band thickening were observed in the HTed Inconel 718 sample [37]. As a result of dislocation curing, grain growth and stress relief, the hardness of cold sprayed deposits usually decreases after HT [24,34,38,41,42]. Figure 2 shows one of the examples that the hardness of cold sprayed Inconel 718 deposits decreased after HT under different cold spray conditions.
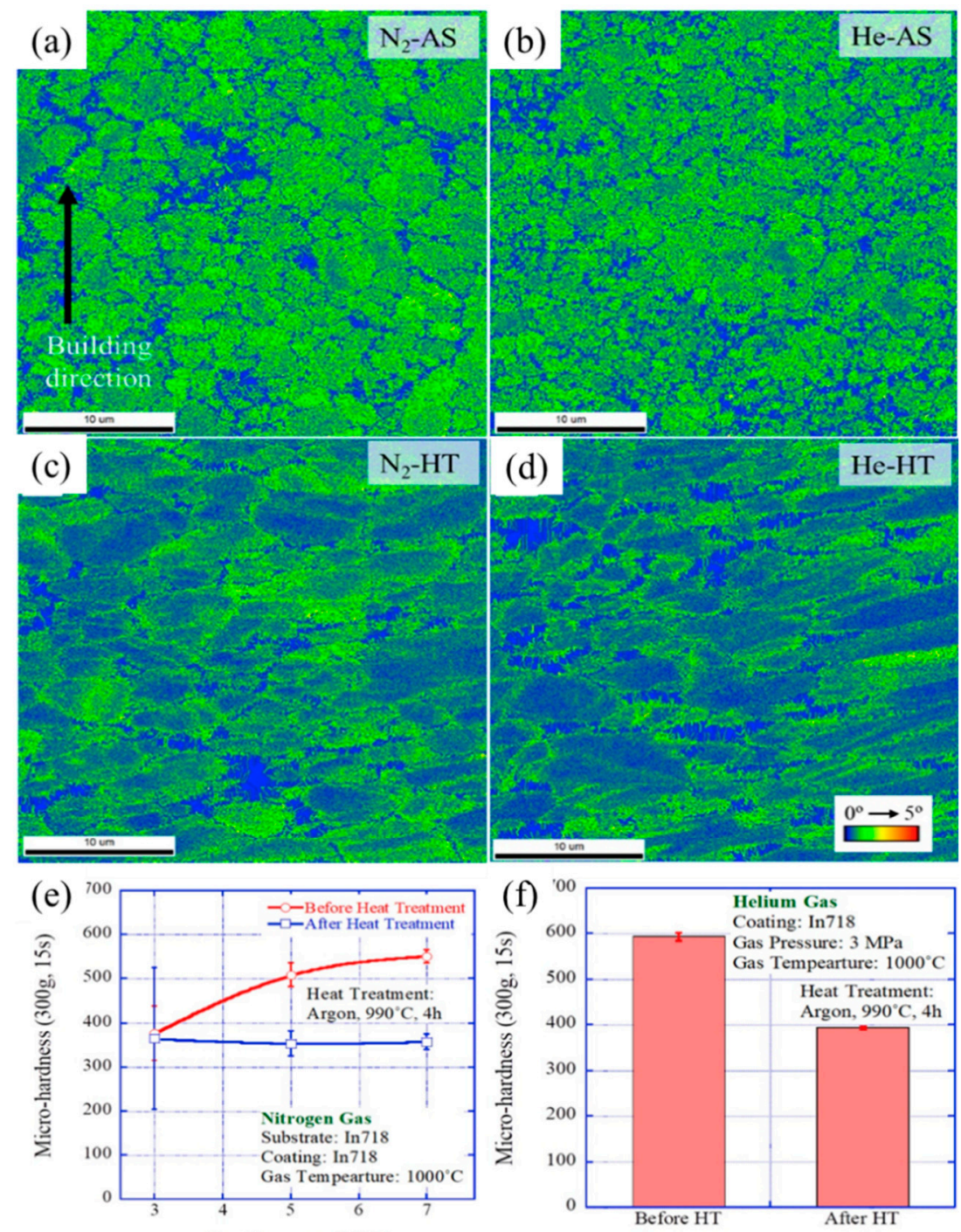

Figure 2. (a-d) Kernel average misorientation (KAM) mappings obtained by EBSD characterization for the Inconel 718 deposits cold sprayed using different propelling gases without or with post heat treatment: (a) $\mathrm{N}_{2}$, as-sprayed; (b) He, as-sprayed; (c) $\mathrm{N}_{2}$, heat treated; (d) He, heat treated; and $(\mathbf{e}, \mathbf{f})$ Microhardness of these cold sprayed Inconel 718 coatings (adapted from reference [38], with permission from ${ }^{\circledR}$ Elsevier). 
It has been well known that metallurgical bonding in cold sprayed coatings only forms partially at particle-particle and particle-substrate interfaces, where 'south pole' exists at the particle-substrate interface and micropores exist at the inter-particle boundaries [43-45]. Therefore, tensile strength and ductility of as-sprayed deposits are usually lower than their bulk counterparts [42,46,47]. After HT, the coating/substrate adhesion strength as well as the coating tensile strength can be significantly improved due to the occurrence of atomic diffusion during HT [38,48]. Notably, the tensile strength of cold sprayed Inconel 718 deposits after HT was comparable to that of the bulk material [38]. Figure 3 shows the effect of HT temperature on the elastic modulus, ultimate tensile strength and elongation of cold sprayed niobium deposits. It was found that the mechanical properties of the cold sprayed niobium deposits after $\mathrm{HT}$ above $1250{ }^{\circ} \mathrm{C}$ were comparable to the bulk niobium material [25]. Observation of fracture morphology showed that the fracture of as-sprayed deposits was mainly dominated by inter-particle de-cohesive brittle failure (Figure 4), which was attributed to insufficient metallurgical bonding, micropores and cracks within the deposits $[26,28,34,37-39,49,50]$. While, the failure of HTed deposits was mainly characterized by intra-particle fracture and ductile dimples could be seen, which, again, proves that enhanced atomic diffusion between splats occurred during HT [28,38,39]. It should be noted that HT environment is an important factor for inter-particle diffusion. Yin et al. [26] found that air-annealed cold sprayed SS316L samples only showed a slight improvement of tensile strength and ductility while the vacuum-annealed SS316L samples displayed comparable mechanical properties to the bulk SS316L material. This was probably because oxide inclusions could be formed at inter-particle interfaces during air annealing, which hindered atomic diffusion [26,51]. Although HT cannot fix all of the defects inside the cold sprayed coatings, the comparable mechanical properties to bulk materials yielded by HT indicate that cold spray combined with post HT is a promising technique for repairing and additive manufacturing applications $[25,28,39,48]$.
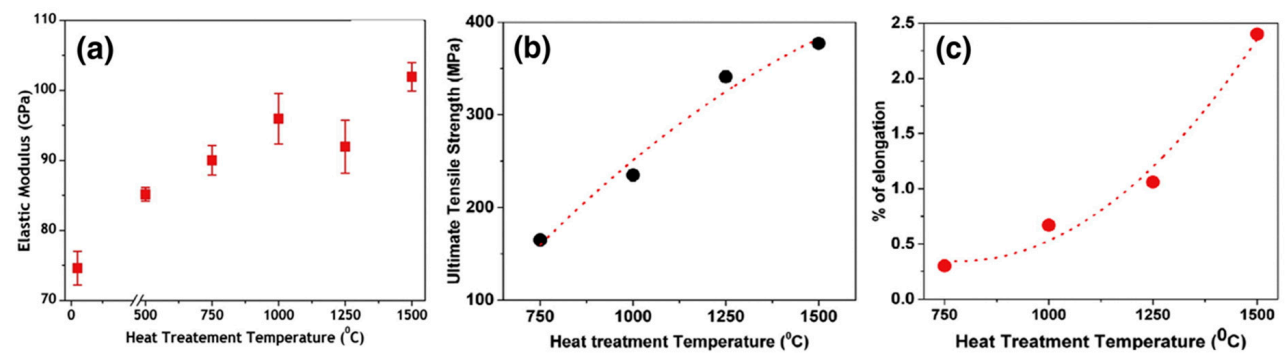

Figure 3. Micro-tensile test results showing (a) elastic modulus; (b) ultimate tensile strength; and (c) percentage of elongation of cold sprayed niobium deposits heat treated at different temperatures (adapted from reference [25], with permission from (C) Elsevier).

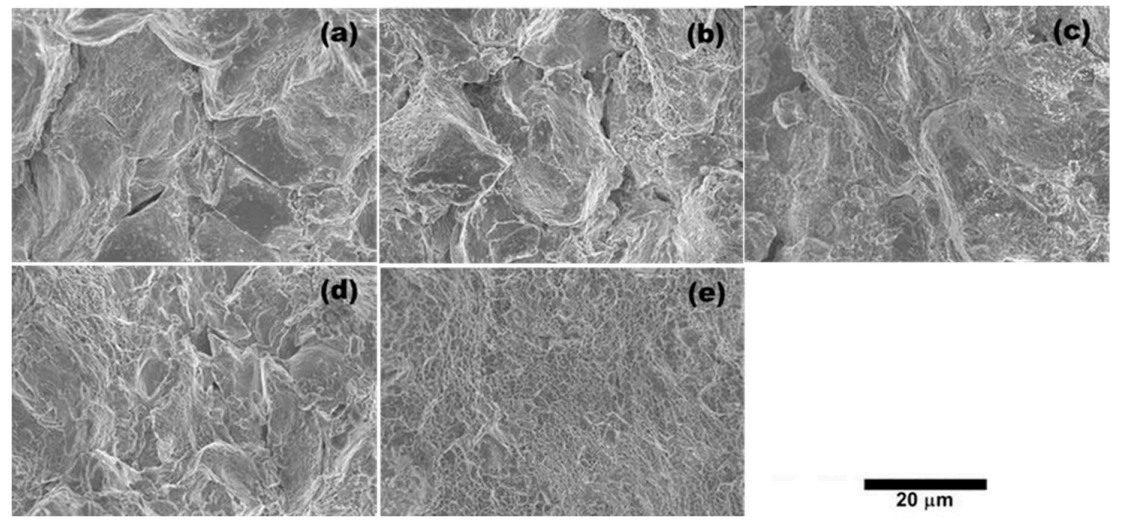

Figure 4. SEM images of fracture surfaces of cold sprayed Inconel 718 deposits: (a) as-sprayed and (b-e) heat treated at (b) $950{ }^{\circ} \mathrm{C} / 2 \mathrm{~h}$, (c) $1010{ }^{\circ} \mathrm{C} / 2 \mathrm{~h}$, (d) $1060{ }^{\circ} \mathrm{C} / 2 \mathrm{~h}$, and (e) $1250{ }^{\circ} \mathrm{C} / 1 \mathrm{~h}$. The almost completely dimple rupture in (e) was ascribed to improved metallurgical bonding and plastic deformation (adapted from reference [39], with permission from ${ }^{\circledR}$ Springer Nature). 
In addition to mechanical property improvement, the modified microstructures of cold sprayed coatings brought by HT can achieve other desirable properties. For instance, the electrical conductivity of cold sprayed $\mathrm{Cu}$ deposits after HT was close to bulk $\mathrm{Cu}$ material [24]. In addition, the soft magnetic performance of cold sprayed $\mathrm{Ni} / \mathrm{FeSiAl}$ soft magnetic composite coating was significantly improved via stress relief and grain growth after HT [37]. The corrosion resistance of cold sprayed niobium deposits was drastically improved to nearly bulk material level after HT, which was attributed to the elimination of pores and inter-particle boundaries [36]. Moreover, the strong anisotropy of the in-plane tensile strength of cold sprayed $\mathrm{Cu}$ deposits could be effectively reduced after proper HT [29]. Currently, investigations on the effects of HT on the properties of cold sprayed deposits other than mechanical properties are still limited; so more studies are needed to expand the understanding of the effects of HT on other properties of cold sprayed deposits.

In addition, HT also exhibits great potential to develop intermetallic compounds or new phases in cold sprayed deposits through atom diffusion of different elements and recrystallization at high temperatures. For example, with the addition of $\mathrm{Ni}$ or $\mathrm{Ti}$ or Fe particles to $\mathrm{Al}$ matrix followed by proper $\mathrm{HT}, \mathrm{Al}-\mathrm{Ni}$ or Al-Ti or Fe-Al compounds were formed, respectively [32,33,52,53]. In addition to the compounds formed within the coatings, an interlayer of $\mathrm{Al}-\mathrm{Mg}$ compound was formed at the interface of Al coating and $\mathrm{Mg}$ alloy substrate after HT [23]. The hardness of the Al-Mg interlayer was similar to that of $\mathrm{Mg}$ alloy and the corrosion resistance of the coating was similar to that of $\mathrm{Al}$ alloy [23]. However, Kirkendall pores were observed at the Al-Mg compound-Al coating matrix after HT [23]. Because Al diffused into the intermetallic layers faster than $\mathrm{Mg}$ and the vacancies moved in the opposite direction of the dominant diffusive flux, the vacancies were being accumulated at the $\mathrm{Al}$ coating and $\mathrm{Al}-\mathrm{Mg}$ compound interface- the Kirkendall effect [23]. Kirkendall pores were also observed at the interface between cold sprayed AA7075 coating and steel DC04 substrate as well as the interface between AA7075 coating and steel 22MnB5 substrate after HT [54]. In addition, Kirkendall pores were also formed at the steel/Al splat interfaces in cold sprayed Al-SS composite coatings after HT, which was also due to the Kirkendall effect [55]. Moreover, for cold sprayed Ti-WC composite deposits, a new phase-TiC was formed after HT due to atom diffusion, which resulted in an improvement of hardness and wear resistance [36]. For cold sprayed $\mathrm{Cu}-4 \mathrm{Cr}-2 \mathrm{Nb}$ deposits, a new $\mathrm{Cr}_{2} \mathrm{Nb}$ phase was formed after HT, which could enhance the pinning effect of grain growth and dislocation movement and thus, improved the micro-hardness and strength of the deposits [30]. Thus, through designing the cold sprayed coating materials systems followed by proper HT, new phases can be formed that either disperse uniformly within the coating or appear at the coating/substrate interface, which can bring new properties and applications to the cold sprayed coatings. Given that, more work can be done on this interesting topic in future.

However, most of the research has focused on conventional furnace HT methods, which is probably not feasible for locally heat treating the cold spray repaired areas in real applications. Our research group explored a more effective and suitable method for local HT of cold sprayed coatings via induction heat treating [37]. The preliminary results showed that the eddy currents promoted atomic diffusion and mass transport, thus resulting in higher flexural strength and ductility of cold sprayed coatings [37]. However, more research work needs to be done to explore novel local heat treatment methods for cold sprayed deposits, which is significantly important for real industry applications.

\section{Friction-Stir Processing Treatment}

Friction-stir processing is a solid-state surface modification technique for producing ultrafine grain structures. In this method, a rotating tool with a specially designed shoulder and pin is plunged into the surface of metal to be modified and then moves along the direction of interest (Figure 5a). The localized frictional heating between the rotating tool and workpiece leads to materials softening around the pin. By material extrusion during a complex flow from the advancing side toward the retreating side, a stirred zone is formed in solid state. Therefore, FSP offers great potential for homogenizing microstructures and eliminating defects in cold sprayed deposits. FSP is also able to break up or 
dissolve the secondary phase particles in the cold sprayed metal matrix composite (MMC) deposits, leading to considerable improvement in mechanical properties. Incorporating cold spray with FSP is a novel two-stage surface engineering process referred to as 'SprayStir' [56,57]. Table 2 summarizes the previous studies regarding the effects of post FSP on cold sprayed coatings.

Figure $5 \mathrm{~b}$ shows the general morphology of cold sprayed coating after FSP [58]. A higher rotation speed was found to be more effective for producing a smooth surface. However, heavy flash occurred at the retreating side and a keyhole was present after pulling out the tool [58]. Typically, the coating thickness is reduced, and various regions are formed within the stir zone after FSP, such as retreating side, pin region and advancing side (Figure $5 b$ ). In addition, the cold sprayed deposits become denser as a result of severe plastic deformation and thickness reduction after FSP.
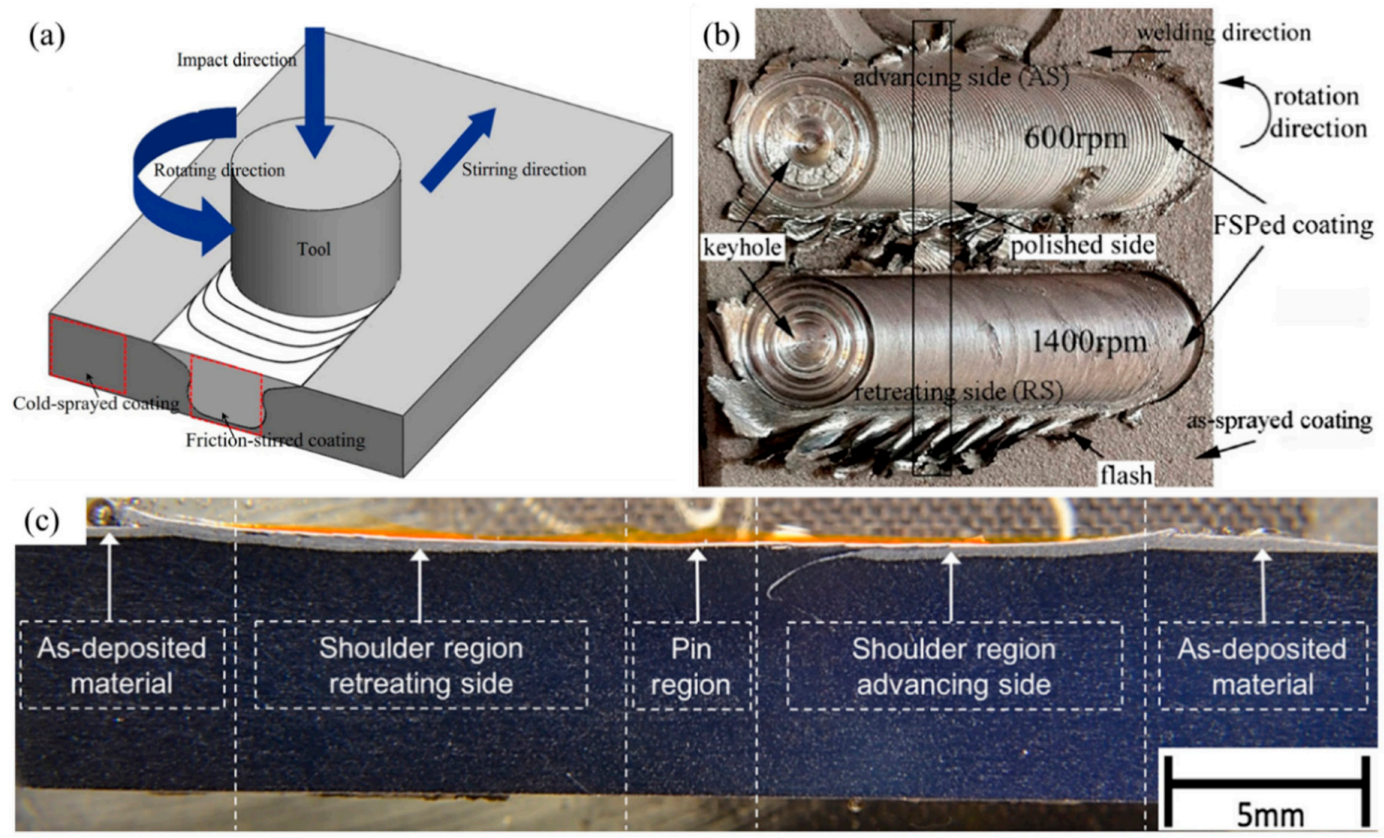

Figure 5. (a) Schematic diagram of FSP on cold sprayed coating (adapted from reference [59], with permission from ${ }^{\circledR}$ Elsevier); (b) general morphologies of as-sprayed SiCp/Al5056 coating after FSP at $600 \mathrm{rpm}$ or $1400 \mathrm{rpm}$ (adapted from reference [58],with permission from ${ }^{\complement}$ Springer Nature); and (c) cross-section view of cold sprayed coating after FSP (adapted from reference [56], with permission from ${ }^{(}$Elsevier). 
Table 2. Effect of friction stir processing on cold sprayed coatings.

\begin{tabular}{|c|c|c|c|}
\hline Coatings & References & FSP Parameters & Main Findings \\
\hline AA7075 & [60] & $\begin{array}{l}\text { Shoulder diameter: } 12 \mathrm{~mm} \text {; Concave shoulder angle: } 3^{\circ} \text {; } \\
\text { Pin diameter: } 1.7 \mathrm{~mm} \text {; Pin height: } 1.5 \mathrm{~mm}\end{array}$ & $\begin{array}{l}\text { After FSP, the hardness of the coatings was improved by } \\
\text { three times and the coating/substrate bonding strength } \\
\text { was improved by material intermixing. }\end{array}$ \\
\hline AA2024/ $\mathrm{Al}_{2} \mathrm{O}_{3}$ composite & [61] & $\begin{array}{l}\text { Stir tool material: H13 steel; Shoulder diameter: } 10 \mathrm{~mm} \text {; } \\
\text { Concave shoulder angle: } 2.5^{\circ} \text {; Pin diameter: } 3.4 \mathrm{~mm} \text {; } \\
\text { Pin height: } 2.9 \mathrm{~mm} \text {; Rotation speed: } 900 \mathrm{rpm} \text {; Traverse } \\
\text { speed: } 50 \mathrm{~mm} / \mathrm{min}\end{array}$ & $\begin{array}{l}\text { FSP significantly reduced the } \mathrm{Al}_{2} \mathrm{O}_{3} \text { particles size and } \\
\text { effectively enhanced the corrosion resistance of the } \\
\text { coatings. }\end{array}$ \\
\hline $\mathrm{AA} 2024 / \mathrm{Al}_{2} \mathrm{O}_{3}$ & [62] & $\begin{array}{l}\text { Stir tool material: H13 steel; Concave shoulder angle: } \\
2.5^{\circ} \text {; Shoulder diameter: } 10 \mathrm{~mm} \text {; Pin diameter: } 2.9 \mathrm{~mm} \text {; } \\
\text { Pin height: } 3.4 \mathrm{~mm} \text {; Rotation speed: } 900-1500 \mathrm{rpm} \text {; } \\
\text { Traverse speed: } 100 \mathrm{~mm} / \mathrm{min}\end{array}$ & $\begin{array}{l}\text { The fragmentation level increased with rotation speed. } \\
\text { FSP could effectively improve the UTS and elongation of } \\
\text { the MMC coatings. }\end{array}$ \\
\hline $\begin{array}{c}\text { WC- } \mathrm{CoCr} / \mathrm{Al}_{2} \mathrm{O}_{3} \\
\left(\mathrm{Cr}_{3} \mathrm{C}_{2}-\mathrm{NiCr} / \mathrm{Al}_{2} \mathrm{O}_{3}\right)\end{array}$ & [56] & $\begin{array}{l}\text { Stir tool material: H13 steel; Concave shoulder angle: } \\
3^{\circ} \text {; Pin diameter: } 2 \mathrm{~mm} \text {; Pin height: } 2 \mathrm{~mm} \text {; Rotation } \\
\text { speed: } 600 \mathrm{rpm} \text {; Traverse speed: } 272 \mathrm{~mm} / \mathrm{min}\end{array}$ & $\begin{array}{l}\text { FSP resulted in substantial refinement of the reinforcing } \\
\text { particles and reduced interparticle spacing for each } \\
\text { reinforcing particle and increased the average hardness of } \\
\text { the coatings. }\end{array}$ \\
\hline WC-CoCr $/ \mathrm{Al}_{2} \mathrm{O}_{3}$ & [57] & $\begin{array}{l}\text { Stir tool material: W-Re/pcBN; Concave shoulder angle: } \\
2^{\circ} / 0 \text {; Shoulder diameter: } 18 \mathrm{~mm} / 25.4 \mathrm{~mm} \text {; Pin diameter: } \\
5 \mathrm{~mm} \text {; Pin height: } 5.7 \mathrm{~mm} / 5.75 \mathrm{~mm} \text {; Rotation speed: } 250 \\
\mathrm{rpm} / 800 \mathrm{rpm} \text {; Traverse speed: } 100 \mathrm{~mm} / \mathrm{min} / 76 \mathrm{~mm} / \mathrm{min}\end{array}$ & $\begin{array}{l}\text { FSP resulted in the dispersion of the as-deposited } \\
\text { WC-CoCr agglomerates and refinement of the } \mathrm{Al}_{2} \mathrm{O}_{3} \\
\text { particles. FSP improved the hardness homogeneity as } \\
\text { well as the anti-erosion performance of the coatings. }\end{array}$ \\
\hline $\mathrm{Ti}$ & [63] & $\begin{array}{l}\text { Stir tool material: WC; Concave shoulder angle: } 2.5^{\circ} \text {; } \\
\text { Shoulder diameter: } 12 \mathrm{~mm} \text {; Rotation speed: } 900 \mathrm{rpm} \text {; } \\
\text { Traverse speed: } 630 \mathrm{~mm} / \mathrm{min}\end{array}$ & $\begin{array}{l}\text { FSP aided the formation of a titanium aluminide }\left(\mathrm{Al}_{3} \mathrm{Ti}\right) \\
\text { intermetallic layer at the Ti coating/Al substrate interface. }\end{array}$ \\
\hline Cu60-Zn40 & [59] & $\begin{array}{l}\text { Concave shoulder angle: } 2.5^{\circ} \text {; Shoulder diameter: } 10 \\
\text { mm; Pin diameter: } 3.4 \mathrm{~mm} \text {; Pin height: } 1.5 \mathrm{~mm} \text {; } \\
\text { Rotation speed: } 1500 \mathrm{rpm} \text {; Traverse speed: } 100 \mathrm{~mm} / \mathrm{min}\end{array}$ & $\begin{array}{l}\text { The friction-stirred coatings contained mainly HAGBs } \\
\text { and twin boundaries with the tensile strength of coating } \\
\text { improved. }\end{array}$ \\
\hline Ni50-Ti50 & [64] & $\begin{array}{l}\text { Stir tool material: W-Re Concave shoulder angle: } 2.5^{\circ} \text {; } \\
\text { Shoulder diameter: } 15 \mathrm{~mm} \text {; Rotation speed: } 1500 \mathrm{rpm} \text {; } \\
\text { Traverse speed: } 100 \mathrm{~mm} / \mathrm{min}\end{array}$ & $\begin{array}{l}\text { After FSP, Ni-Ti intermetallic compounds were formed, } \\
\text { leading to the significantly improved microhardness and } \\
\text { wear resistance of the coatings. }\end{array}$ \\
\hline $\mathrm{SiCp} / \mathrm{Al} 5056$ & {$[58,65]$} & $\begin{array}{l}\text { Stir tool material: W-Re; Concave shoulder angle: } 2.5^{\circ} \text {; } \\
\text { Shoulder diameter: } 10 \mathrm{~mm} \text {; Pin diameter: } 3.4 \mathrm{~mm} \text {; Pin } \\
\text { height: } 2.9 \mathrm{~mm} \text {; Rotation speed: } 600-1400 \mathrm{rpm} \text {; Traverse } \\
\text { speed: } 100 \mathrm{~mm} / \mathrm{min}\end{array}$ & $\begin{array}{l}\text { After FSP, fragmented } \mathrm{SiC} \text { particles were homogenously } \\
\text { distributed in the coatings. The Al matrix particles were } \\
\text { substantially refined to form the fine and equiaxed grains. } \\
\text { The microhardness and anti-friction performance of the } \\
\text { coatings were improved. }\end{array}$ \\
\hline $\mathrm{Al}-\mathrm{Al}_{2} \mathrm{O}_{3}$ & [66] & $\begin{array}{l}\text { Stir tool material: W-Re; Concave shoulder angle: } 3^{\circ} \text {; } \\
\text { Shoulder diameter: } 12 \mathrm{~mm} \text {; Rotation speed: } \\
\text { 894-1723 rpm; Traverse speed: } 88 \mathrm{~mm} / \mathrm{min}\end{array}$ & $\begin{array}{l}\text { After FSP, the coating hardness increased due to the } \\
\text { re-distribution of the } \mathrm{Al}_{2} \mathrm{O}_{3} \text { particles in the coatings. }\end{array}$ \\
\hline
\end{tabular}


Huang et al. [59] studied the grain structures within cold sprayed $\mathrm{Cu}-\mathrm{Zn}$ alloy coatings before and after FSP via EBSD. The Grain Boundary (GB) mapping of the as-sprayed coating is shown in Figure 6a and the corresponding distribution of misorientation angles is shown in Figure 6c. The as-sprayed coating was characterized by $22.6 \%$ High-Angle Grain Boundaries (HAGBs) and 78.4\% Low-Angle Grain Boundaries (LAGBs), which indicated that a high density of dislocations and sub-grains were distributed in the severely deformed grains after cold spraying [59]. However, the coating after FSP presented a large number of HAGBs (90.5\%) and fewer LAGBs (9.5\%) [59], which was mainly attributed to dynamic recrystallization resulting from intense plastic deformation and frictional heating during FSP. The dislocations and LAGBs accumulated with FSP and then transformed into HAGBs via dislocations rearrangement and grain rotations. The formation of a large number of HAGBs after FSP is beneficial for enhancing the strain-hardening capacity and improving tensile strength and ductility due to the fact that HAGBs hinder and block dislocation movement more efficiently [59].
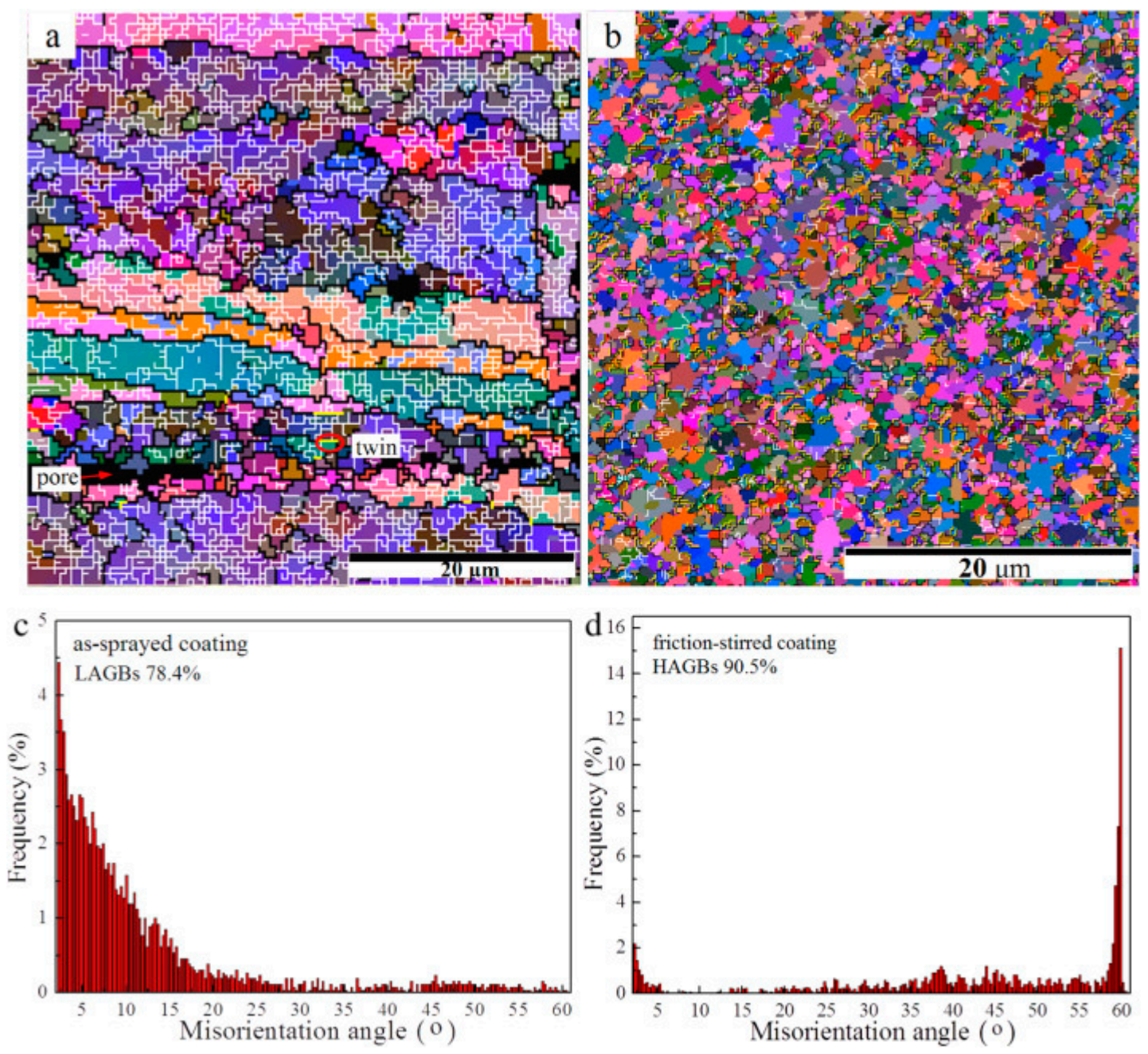

Figure 6. (a,b) EBSD mappings of (a) as-sprayed and (b) FSPed Cu-Zn alloy coatings, where the black, white and yellow lines are corresponding to the HAGBs $\left(\theta \geq 15^{\circ}\right)$, LAGBs $\left(15^{\circ}>\theta>2^{\circ}\right)$, and Twin Bands, respectively. (c,d) Misorientation angle distributions in (c) as-sprayed and (d) FSPed coatings (adapted from reference [59], with permission from ${ }^{\circledR}$ Elsevier).

However, phase transformation may occur within the cold sprayed coatings after FSP, which is caused by material mixing and high-temperature severe plastic deformation induced by the FSP process. Huang et al. [59] investigated the phase evolution of cold sprayed $\mathrm{Cu}-\mathrm{Zn}$ alloy coatings during FSP. The results showed that the majority of $\alpha$-phase (red color) and the limited $\beta^{\prime}$ intermetallic phase 
(yellow color) presented in the as-sprayed coating (Figure 7a). However, the equilibrium $\beta^{\prime}$ phase and the non-equilibrium $\gamma\left(\mathrm{Cu}_{5} \mathrm{Zn}_{8}\right)$ phase were produced after FSP due to the thermo-mechanical effect (Figure $7 \mathrm{~b}$ ). The non-equilibrium $\gamma$ phase formed in these regions could result in the poor mechanical response of the friction-stirred coating. Thus, it should be very careful when FSP is employed to the cold sprayed coatings made of thermally sensitive materials.
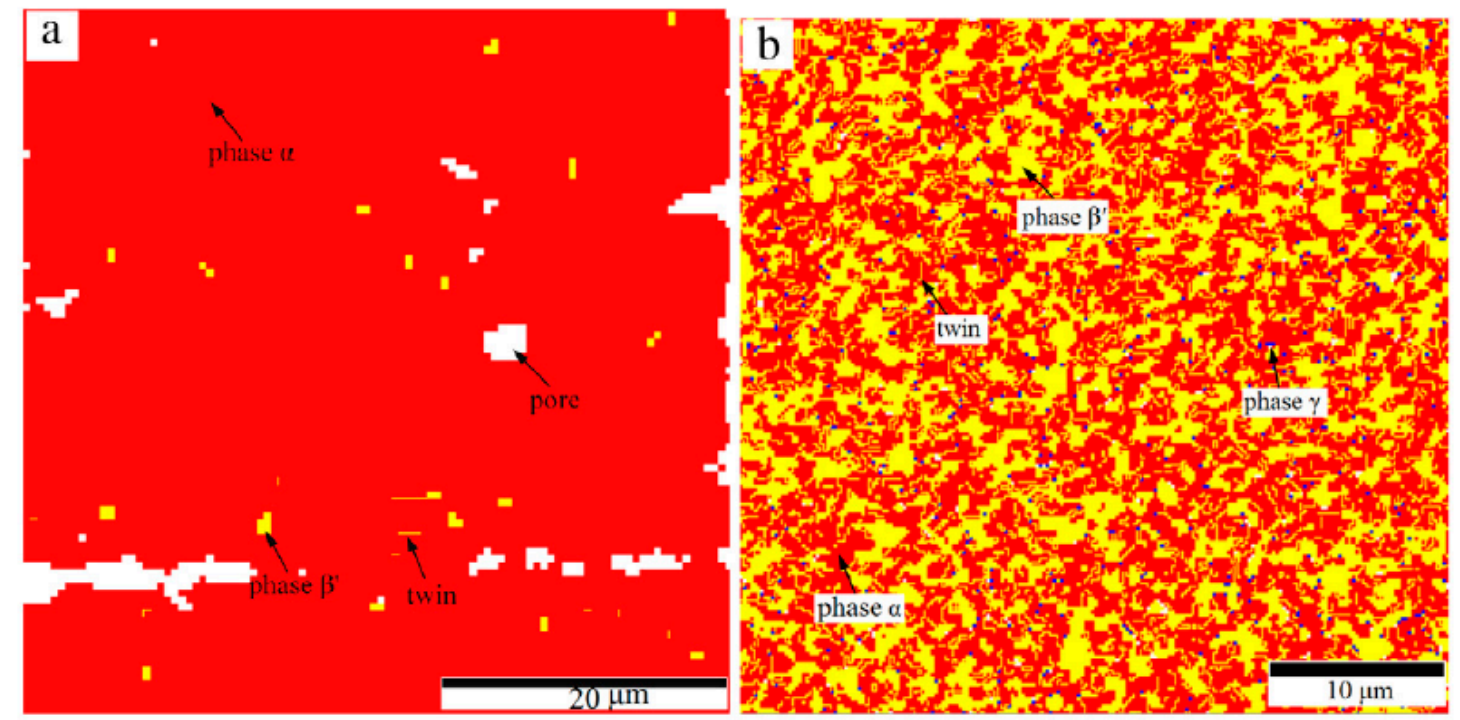

Figure 7. EBSD phase mappings of (a) as-sprayed and (b) friction-stirred $\mathrm{Cu}$ - $\mathrm{Zn}$ alloy coatings, where the red, yellow and blue colors are corresponding to the phases of $\alpha\left(\mathrm{Cu}_{3} \mathrm{Zn}\right), \beta^{\prime}(\mathrm{CuZn})$ and $\gamma\left(\mathrm{Cu}_{5} \mathrm{Zn}_{8}\right)$, respectively (adapted from reference [59], with permission from ${ }^{\circledR}$ Elsevier).

Due to a large amount of heat input during FSP, diffusion and intermetallic phases were observed in cold sprayed coatings after FSP [64]. During FSP, the heat input and strong shear forces generated from the friction would produce severe plastic deformation of the $\mathrm{Ni}$ and $\mathrm{Ti}$ particles, as indicated by the material flow distribution, resulting in the formation of Ni-Ti intermetallic phases (Figure 8) [64]. Moreover, microstructural features at the cold sprayed AA7075/AZ31B interface after FSP showed that diffusion occurred based on the presence of elements between the coating and substrate and a thin intermetallic phase formed under frictional heating and plastic deformation, which promoted material intermixing (Figure 9) [60]. Therefore, after employing FSP, metallurgical bonding between the AA7075 coating and AZ31B substrate was improved by a combination of mechanical mixing and inter-diffusion, which promoted the formation of a thin intermetallic phase [60]. 


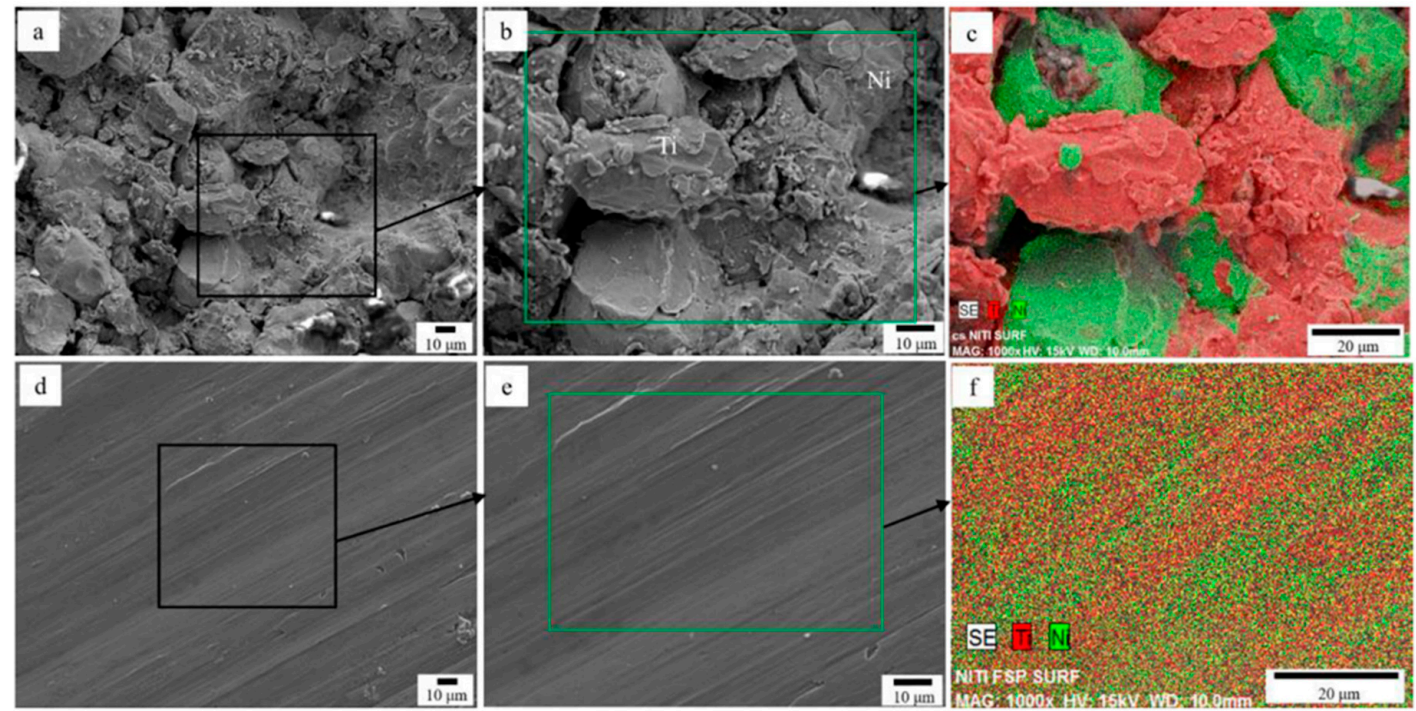

Figure 8. (a,b,d,e) SEM micrographs of surface morphologies of $(\mathbf{a}, \mathbf{b})$ as-sprayed and $(\mathbf{d}, \mathbf{e})$ FSPed Ni-Ti coatings, and (c,f) EDS mappings of Ni and Ti (adapted from reference [64], with permission from (c) Elsevier).
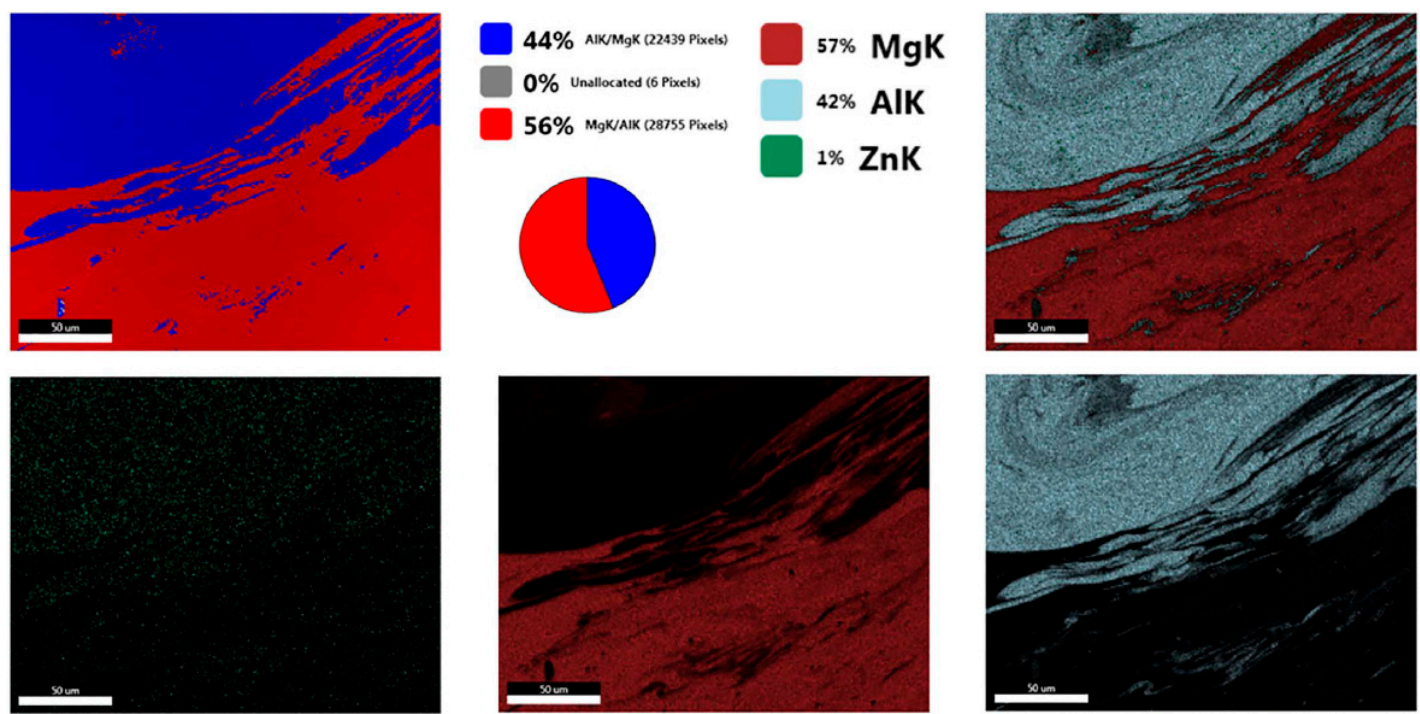

ZnK_ROI (4)

MgK_ROI (70)

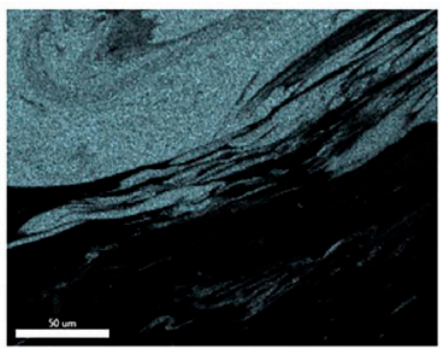

AIK_ROI (53)

Figure 9. EDS elemental mappings from the FSPed AZ31B/AA7075 interface (adapted from reference [60], with permission from ${ }^{\complement}$ Elsevier).

In addition, post FSP could also have a significant effect on cold sprayed MMC coatings. Peat et al. [56] found that the reinforced particle agglomerates in the as-sprayed MMC coatings could be uniformly dispersed by FSP (Figure 10), which was attributed to the shear forces that were applied by the tool. During FSP, the agglomerates were deformed extensively, resulting in the dispersion of individual carbides within the entire matrix. However, it should be noted that the cold sprayed MMC coatings after FSP showed different levels of refinement throughout the coating layer, where a greater level of refinement towards the top surface corresponding to the region that was exposed to higher temperatures and forces from the tool shoulder (Figure 11) [56]. In the middle and bottom regions of the coatings, the level of refinement was moderate and limited due to the decreasing of shear forces from the tool shoulder (Figure 11) [56]. In this case, the FSP parameters should be tailored to better modify the microstructures of cold sprayed MMC coatings. For example, when the rotation speed increased from $900 \mathrm{rpm}$ to $1200 \mathrm{rpm}$ and $1500 \mathrm{rpm}$, the refinement became more prominent with less 
ceramic particles visually [57]. Moreover, additional FSP passes through the MMC coatings could also distribute the cold sprayed reinforcing ceramic particles to a greater extent, even to nanoscale [61]. The refined and uniformly dispersed ceramic particles after FSP can have a positive effect on the strengthening of the metal matrix coatings [57].

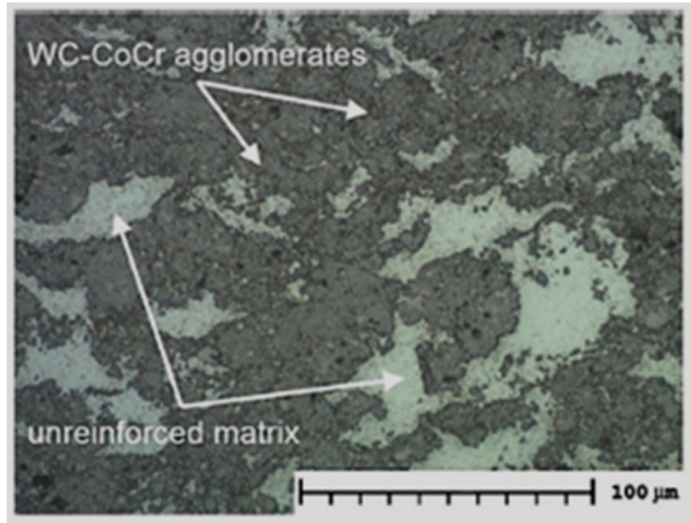

(a)

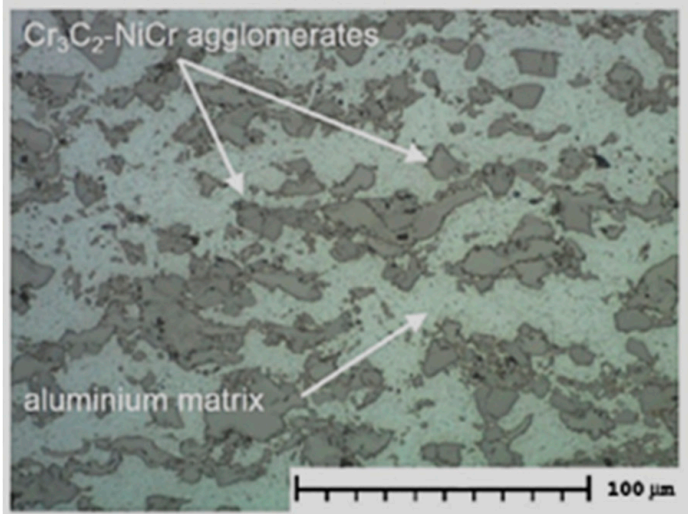

(c)

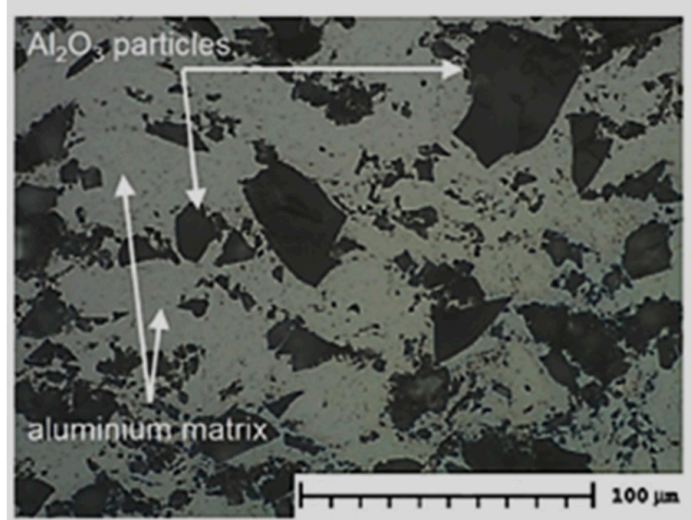

(e)

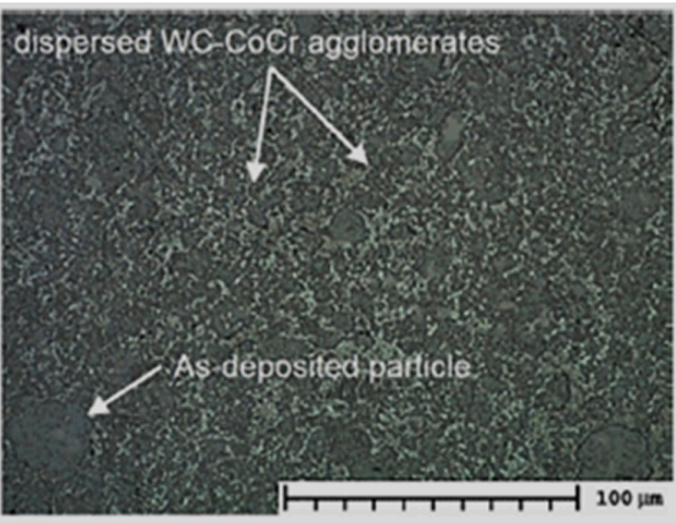

(b)

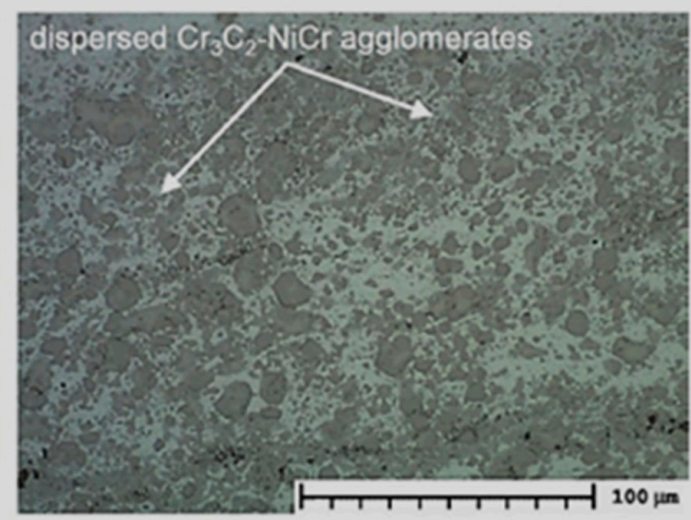

(d)

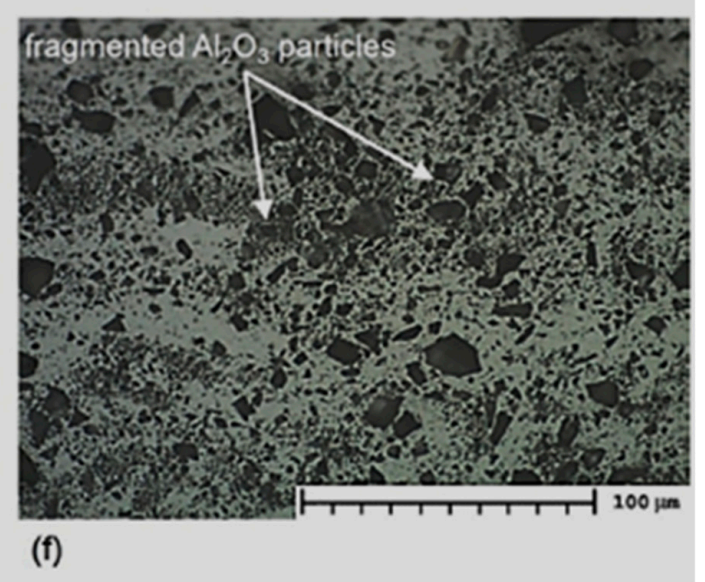

Figure 10. Optical micrographs of the $\mathrm{Al}$ matrix composite coatings: (a) as-deposited WC-CoCr; (b) spray stirred WC-CoCr; (c) as-deposited $\mathrm{Cr}_{3} \mathrm{C}_{2}-\mathrm{NiCr}$; (d) spray stirred $\mathrm{Cr}_{3} \mathrm{C}_{2}-\mathrm{NiCr}$; (e) as-deposited $\mathrm{Al}_{2} \mathrm{O}_{3}$; and (f) spray stirred $\mathrm{Al}_{2} \mathrm{O}_{3}$ (adapted from reference [56], with permission from ${ }^{\complement}$ Elsevier). 


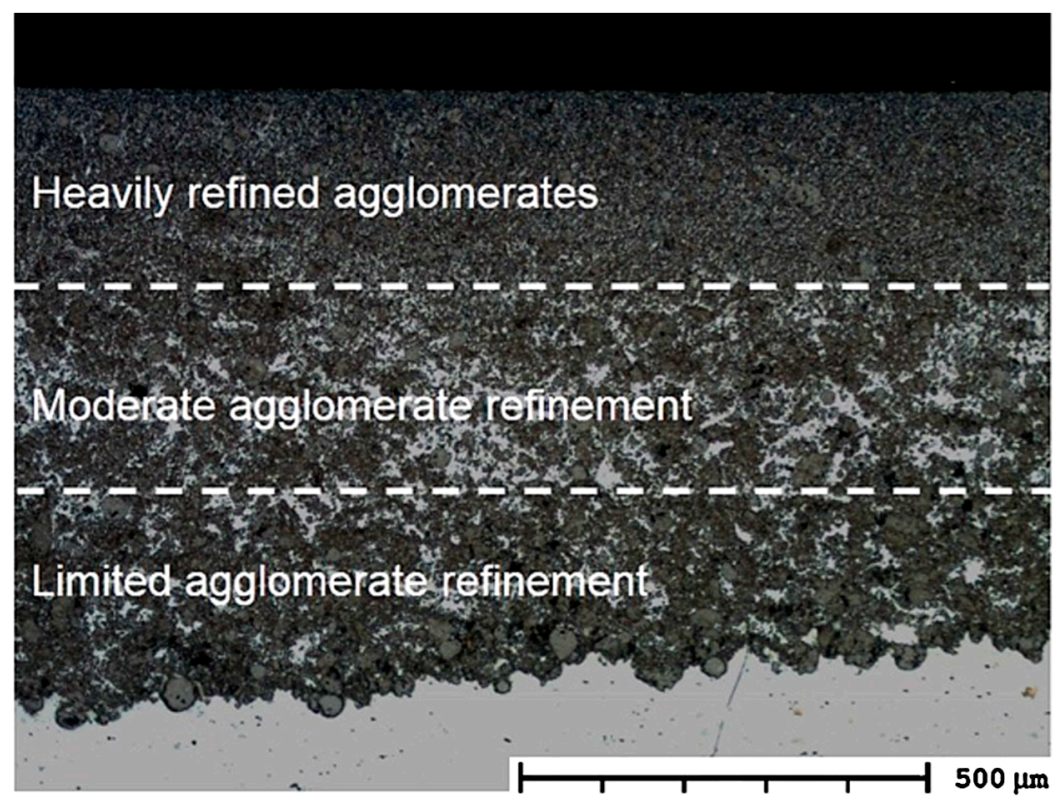

Figure 11. Variations in particle refinement through the depth of spray stirred MMC (adapted from reference [56], with permission from ${ }^{\complement}$ Elsevier).

The mechanical properties of cold sprayed coatings after FSP were also found to be not uniform, varying from the advancing side towards the retreating side due to the differences of the microstructural features [56]. In the middle regions close to the pin, the hardness improvement is usually lower than the regions close to the shoulder edge due to the fact that the outer edge of the tool surface interface experiences higher shear strains and intensified microstructure refinement. In the center region of the stir zone, the hardness is considerably higher due to intermixing, grain structural refinement and the formation of inter-metallic secondary phase and ultrafine reinforcing particles [56]. Huang et al. [58,65] reported that the hardness of FSPed SiC reinforced metal matrix coating was less uniform compared to the as-sprayed one due to the fact that the $\mathrm{SiC}$ particles had been fragmented into different sizes. Therefore, when employing FSP, the uniformity of microstructure and mechanical properties of cold sprayed MMC coatings should be well considered as the FSP process parameters have a great impact upon the distribution of reinforcing particles.

FSP also has a significant effect on the tensile behavior of cold sprayed coatings. Figure 12 shows a comparison on cold sprayed coating tensile strengths before and after FSP [59]. Before FSP, the cold sprayed $\mathrm{Cu}-\mathrm{Zn}$ coating was very brittle (elongation was less than $0.2 \%$ ) with a relatively low tensile strength (around $87 \mathrm{MPa}$ ) due to limited interparticle diffusion during cold spray process. After FSP, the ultimate tensile strength of the cold sprayed Cu-Zn coating dramatically increased to around $257 \mathrm{MPa}$ (Figure 12, the bulk Cu-Zn alloy has a UTS around $381 \mathrm{MPa}$ [59]), which was attributed to the enhanced metallurgical bonding, refined grain structure and phase composition in the coatings [59]. The elongation of the FSPed coating was improved to $0.8 \%$, which was still much lower than that of bulk material (61\%) [59]. Therefore, further studies should be carried out on how to improve the ductility of cold sprayed coatings through FSP. Moreover, it should be noted that using FSP as a post-process treatment method on cold sprayed deposit in real applications is still lacking due to some limitations of FSP, such as geometrical and size requirement of workpiece, keyhole generated at the end of the process, rigid fixture requirement, etc. Thus, more exploration on this topic is needed. 

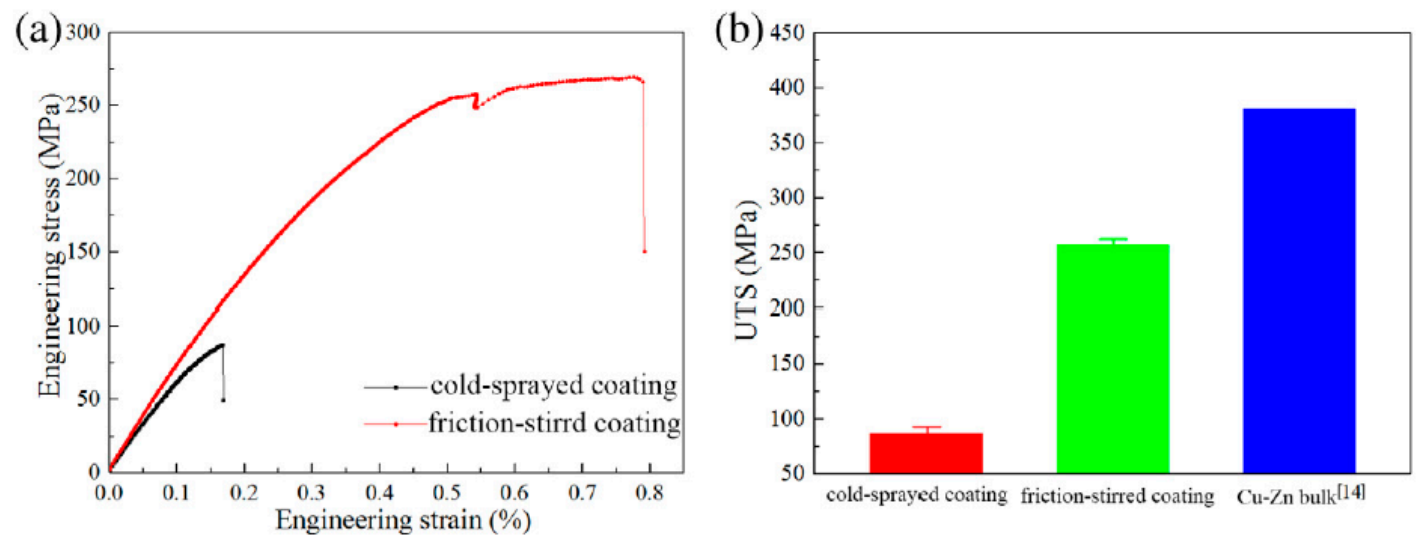

Figure 12. (a) Typical stress-strain curves and (b) ultimate tensile strength of as-sprayed and friction-stirred coatings (adapted from reference [59], with permission from ${ }^{\circledR}$ Elsevier).

\section{Shot Peening Treatment}

Residual stress is a key factor to obtain compact well-adherent and large-scale cold sprayed coatings. It has been reported by Boruah et al. [22] that cold sprayed Ti6Al4V deposits generally started to delaminate after reaching a certain thickness due to the fact that tensile residual stresses were at the top and bottom of the specimen, and compressive stresses were near the interface. Residual stress induced by the cold spray process has been investigated by researchers for various materials from both numerical and experimental aspects [47,67-70]. Shot peening is a mechanical surface treatment in which peening media with sufficient hardness and velocity impact with the work piece surface to cause a surface plastic deformation [71], thus producing a cold-worked material with a high stress in compression. SP is a useful surface treatment method to eliminate surface cracking, induce compressive stress, increase surface hardness and improve fatigue performance, which can be employed as a post-process treatment for cold sprayed coatings. However, there are quite limited studies on SP treatment on cold sprayed coatings, which demonstrates the need for a comprehensive investigation of optimal SP parameters to take advantage of this technique as an effective post treatment method for cold sprayed coatings. This section summarizes the previous studies on the effect of post-process SP on the microstructure, residual stress and mechanical properties of different cold sprayed coatings (Table 3). 
Table 3. Effect of shot peening on cold sprayed coatings.

\begin{tabular}{|c|c|c|c|}
\hline Coatings & References & SP Parameters & Main Findings \\
\hline $\begin{array}{l}\text { Pure } \mathrm{Al} \text { and } \mathrm{Al} / \mathrm{Al}_{2} \mathrm{O}_{3} \\
\text { composite coatings }\end{array}$ & [71] & $\begin{array}{l}\text { Ball Material: } \mathrm{S} 230 \text { cast iron } \\
\text { Diameter: } 0.6 \mathrm{~mm} \\
\text { Stand-of-Distance: } 380 \mathrm{~mm} \\
\text { Pressure: } 1.5 \text { bar } \\
\text { Exposure time: } 33 \mathrm{~s} \\
\text { Coverage: } 200 \%\end{array}$ & $\begin{array}{l}\text { Shot peening was not able to considerably influence the } \\
\text { residual stress state of the coatings. The application of shot } \\
\text { peening was able to induce work hardening to the coating } \\
\text { top layer. }\end{array}$ \\
\hline $\mathrm{Al} 6082$ & [72] & $\begin{array}{l}\text { Ball Material: S230 cast iron } \\
\text { Diameter: } 0.6 \mathrm{~mm} \\
\text { Stand-of-Distance: } 380 \mathrm{~mm} \\
\text { Intensity: "Almen A" strip with 6-8 } \\
\text { (thousandth of an inch) } \\
\text { Coverage: } 100 \% \text { and } 800 \%\end{array}$ & $\begin{array}{l}\text { Post shot peening could not induce compressive residual } \\
\text { stresses in the coatings. Instead, the peening caused } \\
\text { damage in the coatings due to the presence of weakly } \\
\text { bonded particles. The conventional or severe shot peening } \\
\text { as post-treatment was not able to increase the fatigue } \\
\text { strength of the coated specimens. }\end{array}$ \\
\hline NiCrAlY & [73] & $\begin{array}{l}\text { Ball Material: glass bead grit } \\
\text { Diameter: } 0.3 \mathrm{~mm} \\
\text { Stand-of-Distance: } 150 \mathrm{~mm}\end{array}$ & $\begin{array}{l}\text { The surface roughness of the coatings was significantly } \\
\text { reduced after shot peening, which promoted the formation } \\
\text { of a uniform oxide layer on the coating surfaces. }\end{array}$ \\
\hline
\end{tabular}


The surface roughness can be reduced by SP due to further deformation of the particles, and the surface morphology becomes uniform, smooth and compacted after shot peening, as reported by Moridi et al. [72] and Zhang et al. [73]. It was also found that nanoscale grains within the cold sprayed $\mathrm{Al} 6082$ coatings could be induced by post-process SP due to severe plastic deformation [72]. Although a large number of ultrafine grains (in the size of 100-200 nm) were found in the region of particle/particle boundaries in the as-sprayed nickel coating (Figure 13) [74], the microsized or sub-microsized grains were still present in the central regions of the impact particles [74-76]. With the aid of post SP, more nanoscale grains are expected to be produced within the cold sprayed deposits and thus, nanostructured deposits can be formed, which could have excellent properties, such as high strength, good electrical property, superior oxidation and corrosion resistances [77,78].
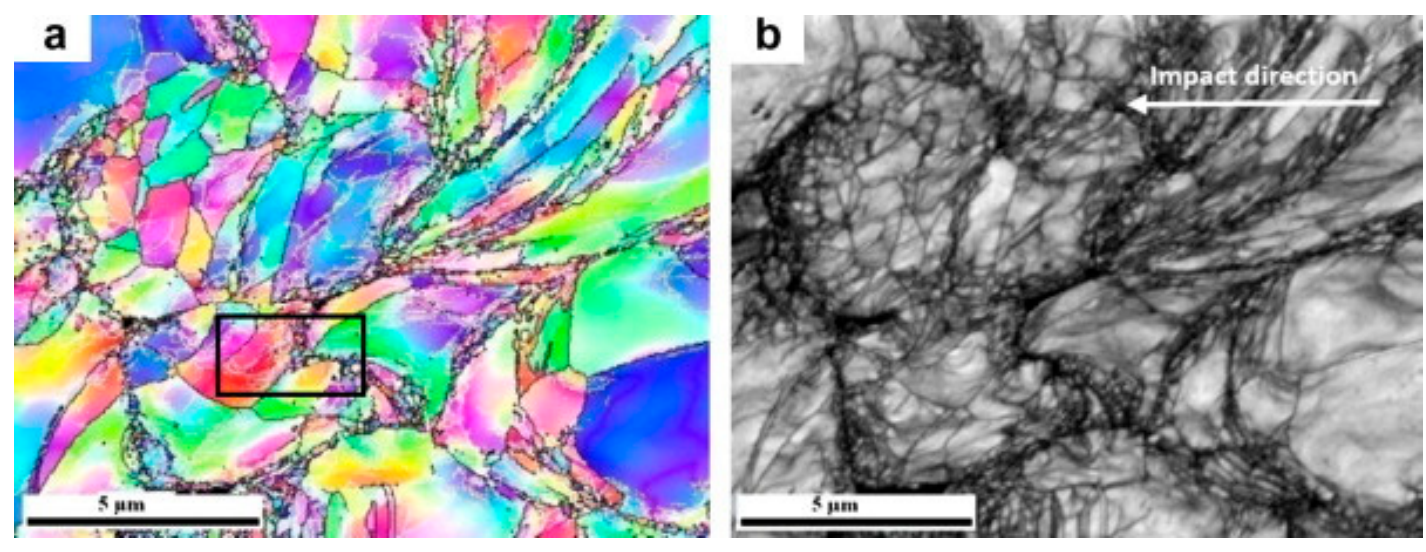

Figure 13. EBSD mappings of the cross-section of as-sprayed nickel coating: (a) Euler angle mapping and (b) pattern quality mapping of the same area as in (a) (adapted from reference [74], with permission from $\left.{ }^{(}\right)$Elsevier).

The investigation of the effect of post process SP on the residual stress of cold sprayed coatings was conducted by Ghelichi et al. [71] and Moridi et al. [72]. The results show that performing SP after cold spray deposition was not able to considerably influence the residual stress state of the cold sprayed coatings. SP only has a minor influence on decreasing the surface residual stress and slightly increasing the compressive stress depth (Figure 14), which is due to the fact that cold sprayed coating is not an ideal continuum and it contains microscopic defects such as non-bonded or weakly bonded particles. Therefore, a large portion of kinetic energy in the subsequent peening is spent to damage the coating and remove some parts of the coating rather than inducing additional work hardening. The material removal could contribute to the partial relaxation of the residual stress. Similar findings were also reported by Moridi et al. [72]. Thus, it is suggested to perform post SP with tailored parameters to avoid removal of coating parts. One possible approach is to employ 'gradient parameters' of SP process to cold sprayed coatings, i.e., firstly, performing lower SP processing parameters to densify the surface layer and enhance interparticle bonding strength, then gradually increasing the SP processing parameters to induce more compressive stress and produce nanosized grains. By doing this, it is possible to achieve the desired properties of cold sprayed coatings step-by-step. Note that this hypothesis has not been experimentally proven in the currently available literature and further experimental investigations can be performed in the future. 
(a)

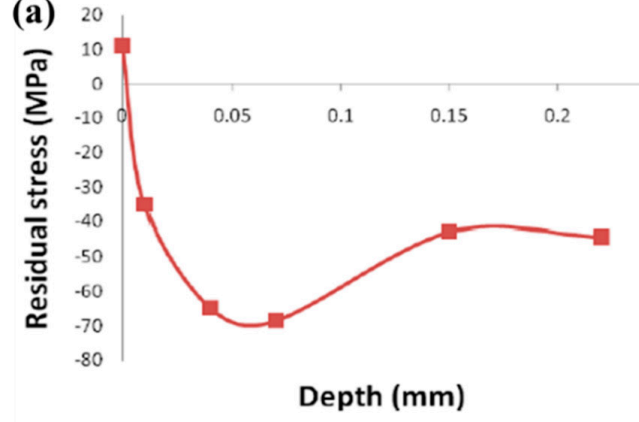

(b)

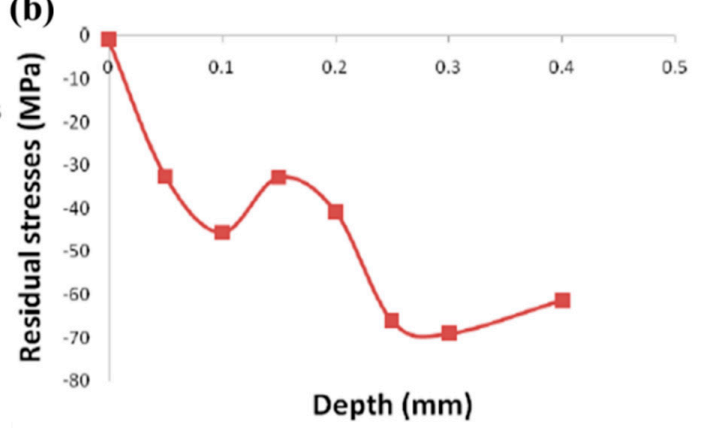

Figure 14. In-plane stress distributions in the cold sprayed $\mathrm{Al}$ coating (a) before and (b) after shot peening [71].

In addition, since post SP can considerably reduce the coating surface roughness, it can be beneficial for retarding crack initiation. However, it was found that the damage caused by post-SP suppressed this effect by producing cracks and thus, no tangible improvement in the rotating bending fatigue strength was observed (Figure 15b) [72]. In addition, post-SP treatments could result in coating delamination from the substrate, especially when high processing parameters were applied. Therefore, post-SP treatments must be performed with caution in order to avoid damage. It was suggested by Moridi et al. [72] that applying SP after HT of cold sprayed coatings was a possible approach to enhance interparticle bonding strength, induce compressive stress, improve coating ductility, and reduce or diminish the possibility of damage by SP. Moridi et al. In addition, [72] reported that performing $\mathrm{SP}$ on the substrates prior to cold spray deposition could result in a better fatigue performance of the specimen, which was attributed to the high depth of compressive residual stresses (Figure 15a). Moreover, SP prior to cold spray deposition was also beneficial for activating the substrate surface and removing the oxide layer originally existing on the substrate surface, which, in turn, could potentially increase the adhesion strength of the coating. Inspired by this, a hybrid approach by combining SP pre-treatment and post-treatment is possible to achieve better results, which can be further investigated.

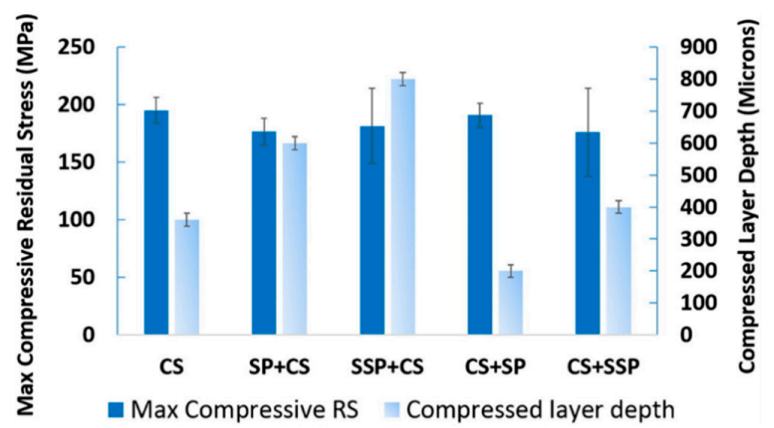

(a)

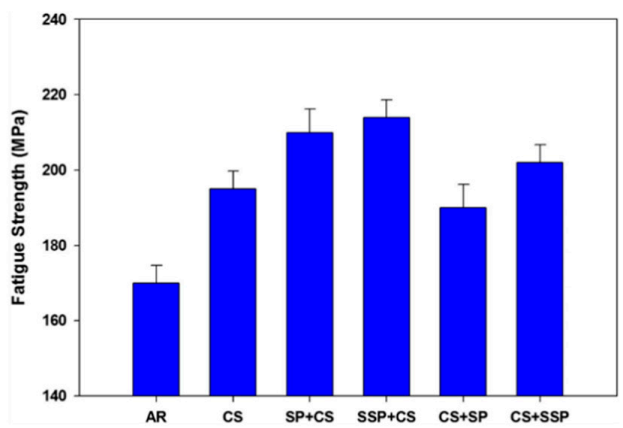

(b)

Figure 15. (a) Maximum compressive residual stresses and depths of compressed layers for different specimens, and (b) fatigue strengths of different specimens (AR: as-received aluminum 6082 bulk specimens, CS: cold sprayed, SP+CS: shot peened substrates before cold spraying, SSP+CS: severely shot peened substrates before cold spraying, CS+SP: shot peened after cold spraying, CS+SSP: severely shot peened after cold spraying) (adapted from reference [72], with permission from $\left.{ }^{(}\right)$Elsevier).

\section{Laser Re-Melting Treatment}

Laser re-melting is an approach to performing a local thermal treatment on the top of the coating to reduce surface roughness and seal open porosities. In the LR process, the heat energy from the laser beam is sufficiently high to melt the sample surface, which is followed by a rapid cooling. Typically, a melting pool is formed after LR, which is governed by the forces of buoyancy due to density difference 
and convection due to surface tension gradients [79]. The bulk material beneath the melting layer acts as a heat sink and the solidification process starts from the sold-liquid interface toward the surface as soon as the laser beam traverses past [79]. During the solidification process, interconnected pores in cold sprayed coatings could be reduced and the splat-structure could be removed. Thus, LR is a promising surface treatment method to promote a homogeneous microstructure, potentially improving the mechanical properties as well as the wear and corrosion resistance of the materials treated [80]. A number of studies have been carried out to investigate the effect of LR on cold sprayed coatings (Table 4).

Astarita et al. [81] and Rubino et al. [82] employed LR to modify cold sprayed pure Ti coatings and it was found that the inter-particle porosity in the top layer of a coating was eliminated (Figure 16a). The densification of the LRed region was due to its melting and micropores escaping to the free surface with the subsequent solidification. Moreover, three typical metallurgical structure zones were formed in the LRed Ti layer, i.e., the remelted zone (RZ), the heat affected zone (HAZ) and the base material (BM) (Figure 16). For the BM zone, thin lamellae were observed due to high kinetic energy impact and severe plastic deformation during cold spray deposition. In the HAZ, coarser lamellae were formed due to certain heat input, which resulted in grain growth. A transition zone was formed between the $\mathrm{BM}$ and HAZ zones (Figure 16d). In the RZ, equiaxial $\alpha$ grains and martensitic acicular $\alpha$ grains were formed due to the rapid cooling during the LR process. Similarly, a transition zone was observed between the RZ and HAZ (Figure 16f), where some acicular martensitic $\alpha$ grains were formed due to the high cooling rate.
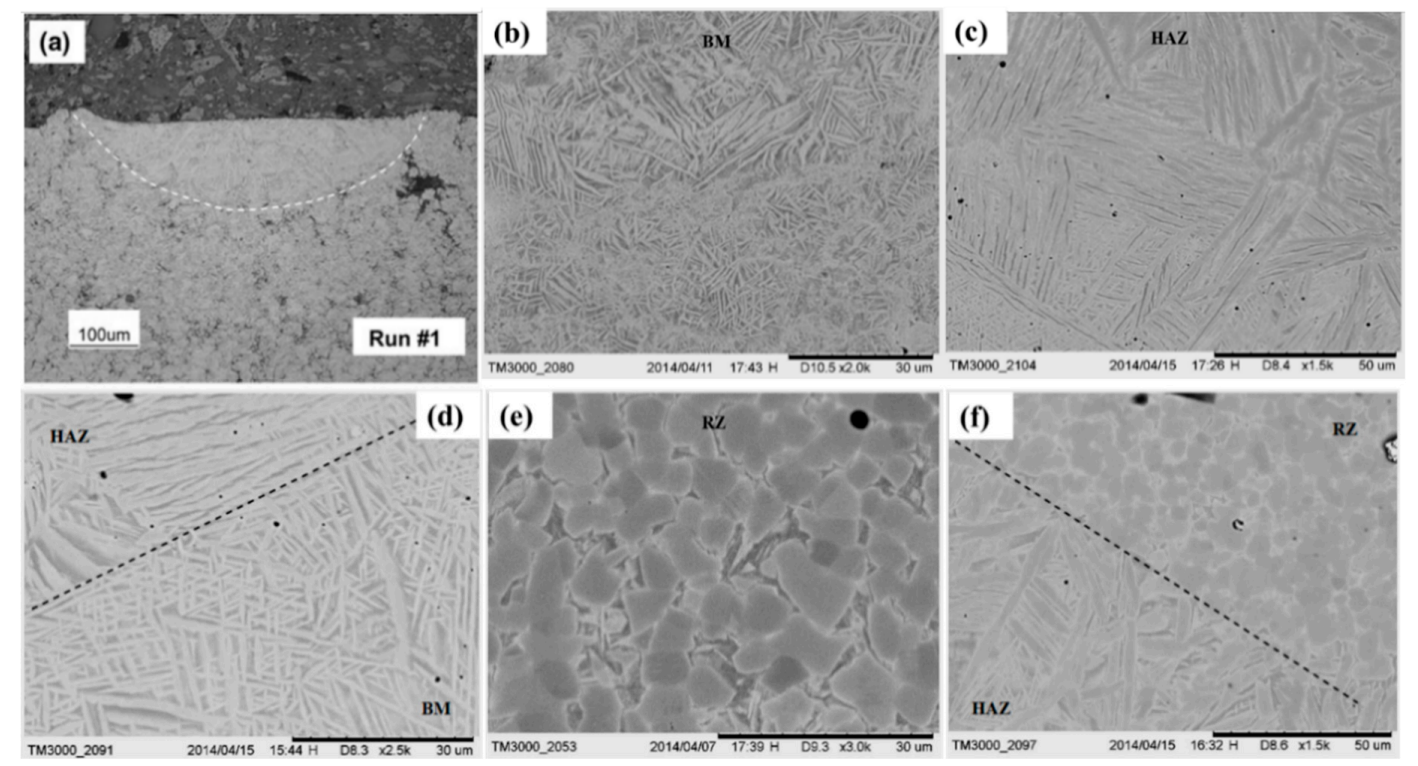

Figure 16. (a) Optical micrograph of the cross section of cold sprayed Ti coating after laser re-melting (adapted from reference [83], with permission from ${ }^{\circledR}$ Springer Nature), and (b-f) SEM micrographs of cold sprayed Ti coating at different zones: (b) Base Material (BM); (c) Heat Affected Zone (HAZ); (d) transition zone between BM and HAZ; (e) Remelted Zone (RZ); and (f) transition zone between HAZ and RZ (adapted from [81], with permission from ${ }^{\circledR}$ Elsevier).

These microstructural features presented in different zones would in turn influence the mechanical properties of the coatings [81]. The hardness of the HAZ was lower than the one measured in the $\mathrm{BM}$ due to the formation of the coarser lamellae in the HAZ (Table 5). However, the RZ showed a higher hardness than the BM and HAZ due to the presence of acicular martensitic $\alpha$ grains within the RZ (Table 5). The top surface oxide layer produced by LR was much harder than the BM, which was beneficial for improving the wear and corrosion resistances. Surface oxides may also reduce the material's ductility and ability to resist fatigue and creep [83]. Astarita et al. [81] and Rubino 
et al. [82] also studied the effect of laser scan speed on cold sprayed Ti coatings. It was found that material vaporization occurred and surface cracks were produced when the laser scan speed was very low due to excessive heat input. In contrast, there was no remarkable modification when the scan speed was too high due to insufficient heat input. In addition, Poza et al. [84] also investigated the effect of different laser scan speeds on the mechanical properties of cold sprayed Inconel 625 coatings. The results showed that the LR layer depth decreased with a higher scan speed due to lower heat input. Moreover, coating porosity was significantly reduced after LR, which resulted in a higher elastic modulus. With the increase of the laser scan speed, the elastic modulus of the LRed coating remained similar (Figure 17). However, the LRed coating exhibited a lower hardness due to the presence of columnar dendritic microstructure as the highly deformed as-sprayed microstructure was relaxed after LR. With the increase of the laser scan speed, the hardness drop was more obvious (Figure 17), which was attributed to the diffusion of Fe element from the substrate into the coating when the laser scan speed was lower (more heat input). Thus, LR not only affects the coating layer but also the reaction between the coating and the substrate via sufficient heat input.
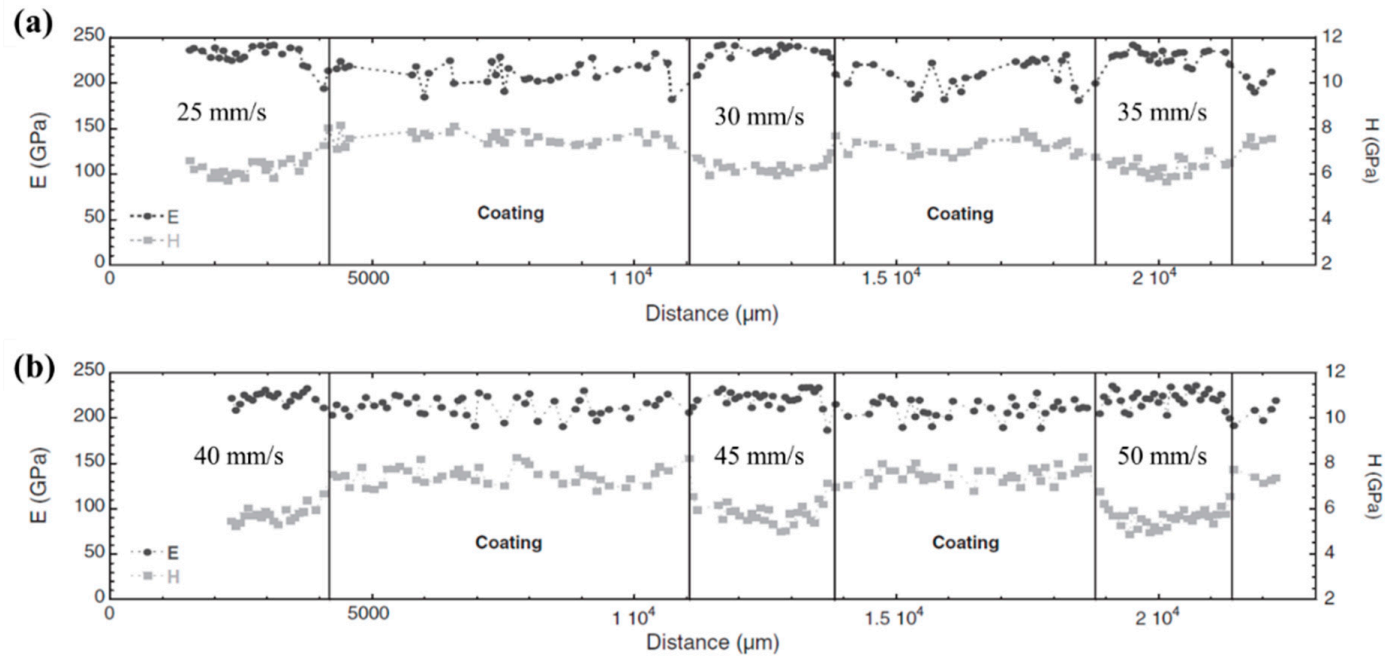

Figure 17. Elastic modulus and hardness values obtained from indentation lines carried out along the transversal directions of the re-melted beads subjected to (a) high energetic conditions: $25 \mathrm{~mm} / \mathrm{s}$, $30 \mathrm{~mm} / \mathrm{s}$ and $35 \mathrm{~mm} / \mathrm{s}$, and (b) low energetic conditions: $40 \mathrm{~mm} / \mathrm{s}, 45 \mathrm{~mm} / \mathrm{s}$ and $50 \mathrm{~mm} / \mathrm{s}$ (adapted from reference [84], with permission from $\left.{ }^{(}\right)$Elsevier).

Apart from laser scan speed, Khun et al. [80] studied the effect of laser power on the microstructure and mechanical properties of cold sprayed Ti64 coatings. It was found that a higher laser power resulted in surface shrinkage and surface cracks along the laser irradiated lines due to rapid cooling. Although rapid cooling resulted in higher surface hardness and wear resistance of the Ti64 coatings, the formation of surface cracks might be harmful to other material properties. Thus, it is worth noting that LR processing parameters (laser power, spot diameter and traverse speed) should be properly optimized so that the heat input and temperature distribution can be controlled for achieving acceptable microstructure and mechanical properties. 
Table 4. Effect of laser re-melting on cold sprayed coatings.

\begin{tabular}{|c|c|c|c|}
\hline Coatings & References & LR Parameters & Main Findings \\
\hline $\mathrm{Ti}$ & {$[81,82]$} & $\begin{array}{l}\text { Spot diameter: } 2 \mathrm{~mm} \\
\text { Scan speed: } 10-1000 \mathrm{~mm} / \mathrm{s} \\
\text { Laser power: } 200 \mathrm{~W}\end{array}$ & $\begin{array}{l}\text { After LR, three different metallurgical zones were observed: a } \\
\text { re-melted zone (RZ), a heat affected zone (HAZ) and the base } \\
\text { material (BM). }\end{array}$ \\
\hline CP-Ti grade 2 & [83] & $\begin{array}{l}\text { Spot diameter: } 0.3-1.08 \mathrm{~mm} \\
\text { Scan speed: } 21.6-48.3 \mathrm{~mm} / \mathrm{s} \\
\text { Laser power: } 440-1000 \mathrm{~W}\end{array}$ & $\begin{array}{l}\text { The laser-treated regions were pore-free with the equiaxed grains. } \\
\text { The laser-treated Ti coatings performed like a high-quality barrier } \\
\text { layer that improved their anti-corrosion performance. }\end{array}$ \\
\hline Ti-6Al-4V & [80] & $\begin{array}{l}\text { Spot diameter: } 1 \mathrm{~mm} \\
\text { Scan speed: } 20 \mathrm{~mm} / \mathrm{s} \\
\text { Laser power: } 50-200 \mathrm{~W}\end{array}$ & $\begin{array}{l}\text { The laser treated Ti64 coatings with a higher laser power had a higher } \\
\text { surface hardness. The tribological properties of the laser treated Ti64 } \\
\text { coatings were significantly influenced by the laser power. }\end{array}$ \\
\hline $\mathrm{Al}$ & [85] & $\begin{array}{l}\text { Spray distance: } 250 \mathrm{~mm} \\
\text { Spot diameter: } 5 \mathrm{~mm} \\
\text { Laser power: } 800 \mathrm{~W} \\
\text { Flow rate of Ar gas: } 8 \mathrm{~L} / \mathrm{min}\end{array}$ & $\begin{array}{l}\text { After LR, the fine porosities and micro-cracks in the coatings were } \\
\text { eliminated, and the grains were refined. The Al coating hardness and } \\
\text { wear resistance were enhanced after LR. }\end{array}$ \\
\hline Inconel 625 & [84] & $\begin{array}{l}\text { Scan speed: } 25-50 \mathrm{~mm} / \mathrm{s} \\
\text { Heat input: } 14-28 \mathrm{~J} / \mathrm{mm} \\
\text { Laser power: } 700 \mathrm{~W}\end{array}$ & $\begin{array}{l}\text { After LR, the coating porosity was reduced and the coating elastic } \\
\text { modulus increased, while the coating hardness was reduced due to } \\
\text { the formation of a columnar dendritic microstructure. }\end{array}$ \\
\hline Al-Si coating & [86] & $\begin{array}{l}\text { Spot diameter: } 40 \mu \mathrm{m} \\
\text { Hatch distance: } 50 \mu \mathrm{m} \\
\text { Scan speed: } 1000 \mathrm{~mm} / \mathrm{s} \\
\text { Laser power: } 200-300 \mathrm{~W}\end{array}$ & $\begin{array}{l}\text { After LR, the coating microstructure was significantly refined, and } \\
\text { the coating surface roughness was lowered. An Al phase } \\
\text { supersaturated with Si was formed in the coatings after FSP. }\end{array}$ \\
\hline
\end{tabular}


Table 5. Vickers microhardnesses of cold sprayed Ti coatings at different zones after laser re-melting with different laser scan speeds (adapted from reference [81], with permission from ${ }^{\circledR}$ Elsevier).

\begin{tabular}{cccc}
\hline \multirow{2}{*}{ Laser Scan Speed (mm/s) } & \multicolumn{3}{c}{ Microhardness (HV) } \\
\cline { 2 - 4 } & RZ & HAZ & BM \\
\hline 200 & 480 & 130 & \\
400 & 475 & 134 & \\
600 & 485 & 128 & 160 \\
800 & 468 & 125 & \\
1000 & 473 & 135 & \\
\hline
\end{tabular}

Moreover, the LRed coating showed that a shift in the open circuit potential (OCP) and corrosion potential $\left(\mathrm{E}_{\mathrm{corr}}\right)$ values toward the noble direction and a significant decrease of the potentiodynamic polarization current $\left(\mathrm{I}_{\mathrm{pp}}\right)$ (Figure 18) [83]. These results indicated that the LRed coating performed better in anti-corrosion compared to the as-sprayed coating, which could be attributed to the dense LR layer and the protective surface oxide film. However, the corrosion behavior of the LRed Ti coating is different from that of the bulk Ti and the corrosion mechanism of the LRed coating layer is still not clear yet, which is recommended to be further investigated. In particular, the unique microstructural features and the role of surface oxide film on the LRed layer should be further addressed.
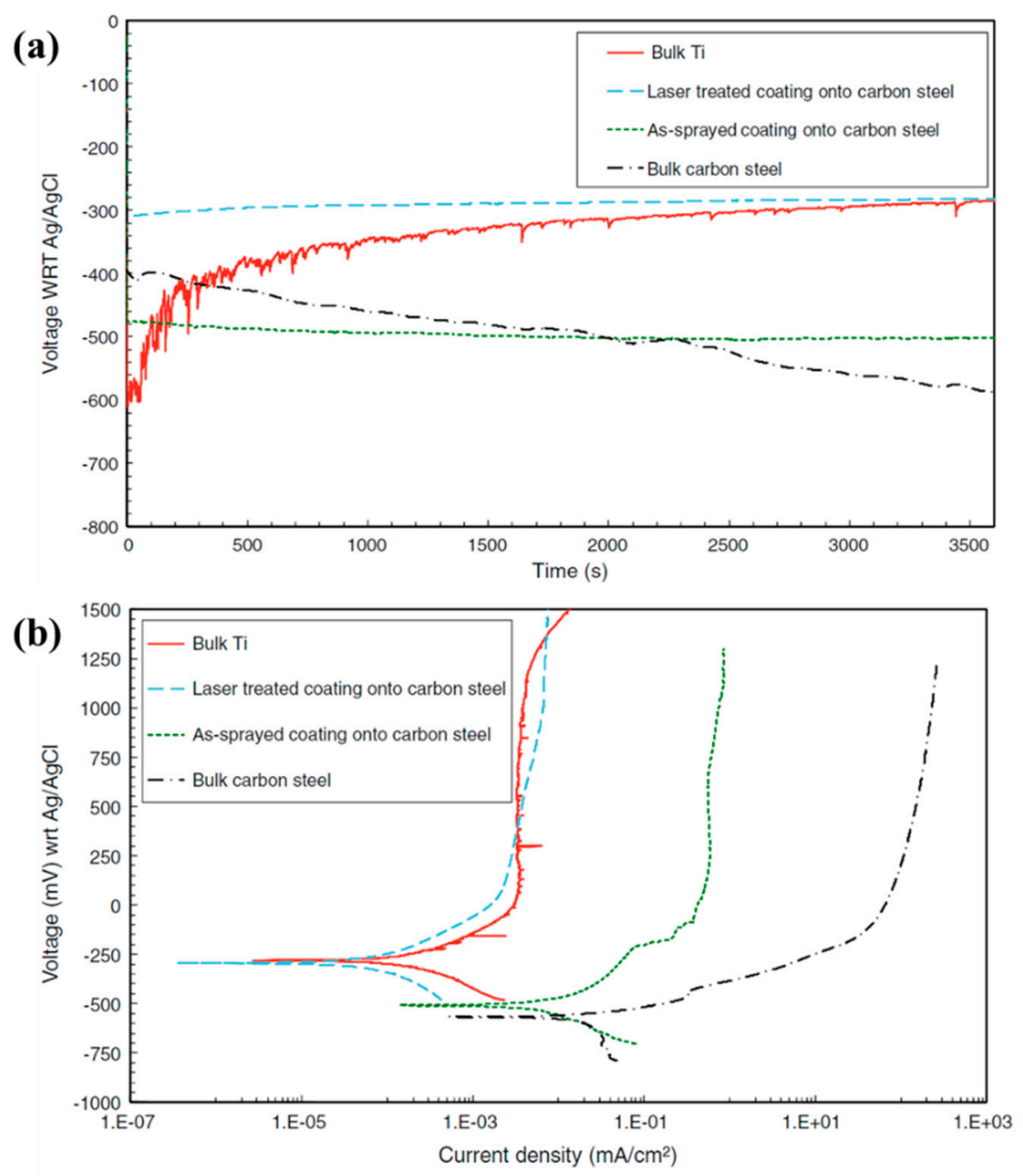

Figure 18. (a) Open circuit potentials (OCPs) and (b) potentiodynamic polarization scans of bulk Ti, carbon steel, as-sprayed Ti coating (on carbon steel), and laser-treated Ti coating measured in an aerated $3.5 \% \mathrm{NaCl}$ solution (adapted from reference [83], with permission from ${ }^{\circledR}$ Springer Nature). 
In contrast to the work done on cold sprayed pure metal or alloy coatings, Kang et al. [86] investigated the effect of LR on cold sprayed Al-Si composite coatings. In the as-sprayed Al-Si coating, there was little or no interaction between the Si particles and the Al matrix (Figure 19a), which was due to the mechanical bonding nature between these two phases [86]. After LR, the microstructure of the as-sprayed deposit was significantly refined and the Si particles were not visible within the LRed layer. Because the Al-Si mixture was completely melted (Al melting point: $\sim 660^{\circ} \mathrm{C}$, Si melting point: $\sim 1414^{\circ} \mathrm{C}$ ) and then rapidly cooled down to produce a Si containing supersaturated $\mathrm{Al}$ phase [86]. The formation of the $\mathrm{Si}$ containing supersaturated $\mathrm{Al}$ phase could effectively improve the performance of the $\mathrm{Al}-\mathrm{Si}$ coating via lattice distortion and grain refinement. This phenomenon may raise a new research topic on combining cold spraying hybrid materials (composed of different particulates) with laser re-melting to yield new phases in the coating. In addition, equiaxed grains were observed in the top region, while columnar grains constituting the major grain structure were seen in the bottom region, and a mixture of equiaxed and vertical columnar grains was observed in between (Figure 19e-g). However, several big pores appeared in the region between the LRed layer and the remaining cold sprayed deposit (Figure 19b-d), which could be attributed to the Kirkendall effect $[86,87]$ and the coalescence of the smaller pores and could negatively impact the coating's integrity and physicochemical properties as well. Thus, more detailed work can be carried out on how to eliminate the big pores formed in the region between the LRed layer and the remaining layer.

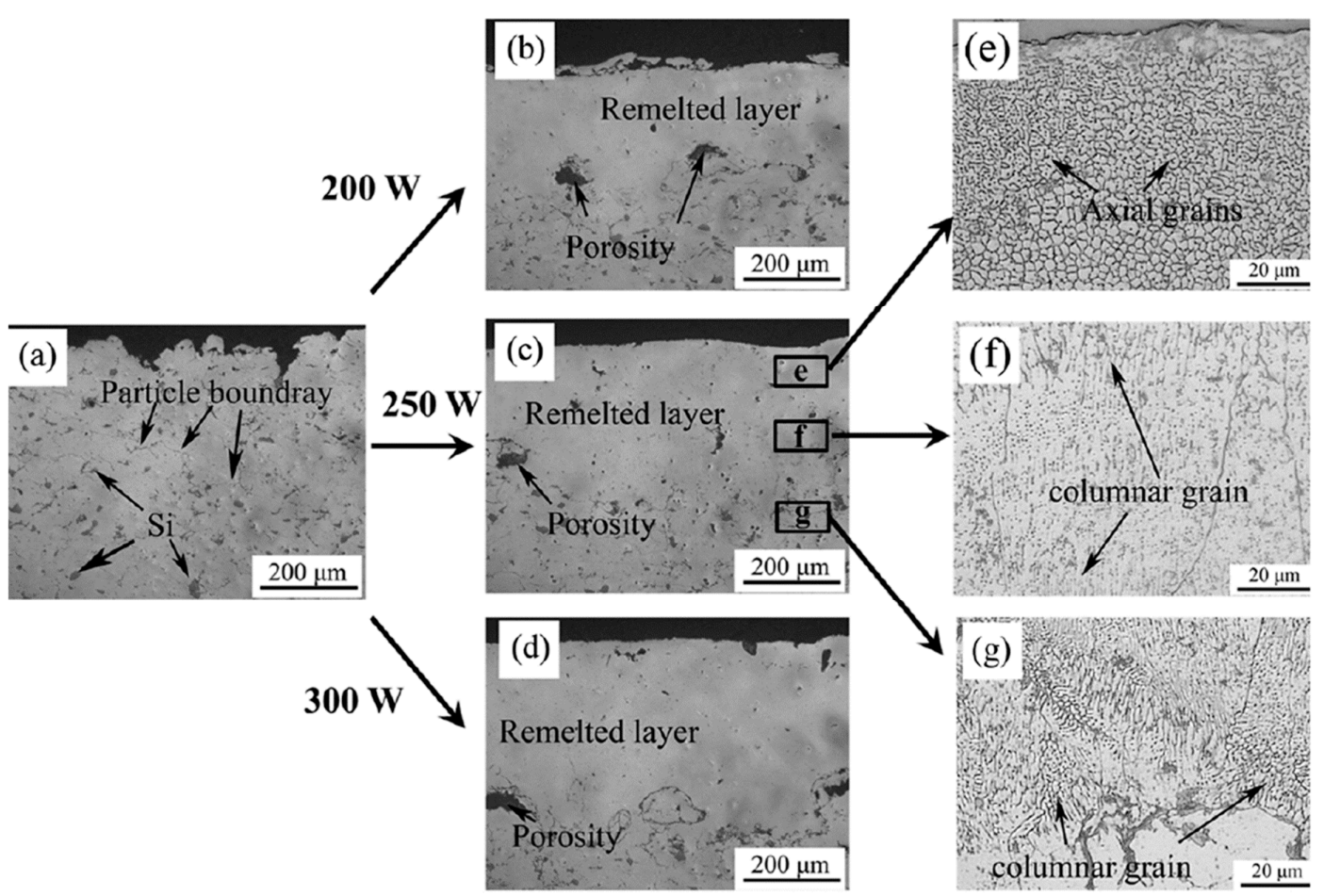

Figure 19. (a-d) Cross-section views of (a) as-sprayed Al-Si and (b-d) same sample after laser surface re-melting at 200, 250 and $300 \mathrm{~W}$, respectively, and (e-g) microstructures corresponding to the respective top, middle and bottom portions of the sample shown in (c) (adapted from reference [86], with permission from ${ }^{(C)}$ Elsevier).

\section{Other Post-Process Treatments}

Apart from the above-mentioned post process treatment methods, there are also some other means, which will be reviewed in this section (as summarized in Table 6). Hot rolling is a thermo-mechanical treatment process in which metal is heated above the recrystallization temperature and plastically deformed in a rolling operation [88] (Figure 20a). Tariq et al. [88] conducted a study on the effect of post hot rolling on cold sprayed $\mathrm{B}_{4} \mathrm{C} / \mathrm{Al} \mathrm{MMC}$ deposits. The results showed that this method 
could efficiently heal out the splat boundaries and improve the mechanical properties of the $\mathrm{B}_{4} \mathrm{C} / \mathrm{Al}$ MMC deposits. The thickness of the $\mathrm{B}_{4} \mathrm{C} / \mathrm{Al}$ MMC deposits was significantly reduced after hot rolling. Microstructural investigation revealed that the composites were composed of a hybrid microstructure (containing extensively refined recrystallized grains and sub-structured grains) after hot rolling due to continuous dynamic recrystallization (Figure $20 \mathrm{~b}-\mathrm{e}$ ). In addition, the bonding between $\mathrm{Al} / \mathrm{Al}$ splats and $\mathrm{B}_{4} \mathrm{C} / \mathrm{Al}$ interfaces was dramatically improved due to enhanced diffusion activity. As a result, the yield strength, ultimate tensile strength and elongation of the MMC deposits were simultaneously enhanced. The samples after hot rolling displayed higher values of ultimate tensile strength ( 131 MPa) and elongation $(\sim 5.2 \%)$ than the corresponding values for the as-sprayed $(\sim 37 \mathrm{MPa}, \sim 0.3 \%)$ and conventionally heat treated ( $60 \mathrm{MPa}, 1.6 \%)$ samples (Figure 20f) [88]. In addition to the above work, the same research group has also applied hot rolling on cold sprayed Si/A380 MMC deposits [89]. The results showed that the hot rolled samples had better tensile strength and ductility compared to their as-sprayed state, which could be attributed to the progressive elimination of inter-particle defects. Furthermore, the results revealed the uniform distribution of Si particles in the Al matrix, which was beneficial to improve the coating mechanical strength [89]. Therefore, hot rolling appears to be an effective and simple post treatment method that can be applied to a variety of as-sprayed coatings for improving their mechanical properties. However, this method is probably only applicable to free-standing cold sprayed deposits.

(a)

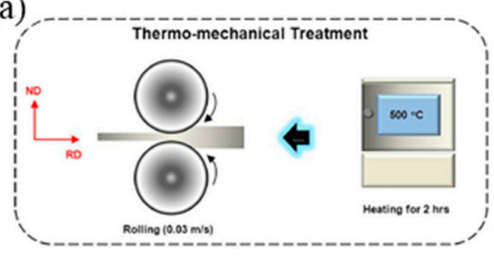

(f)

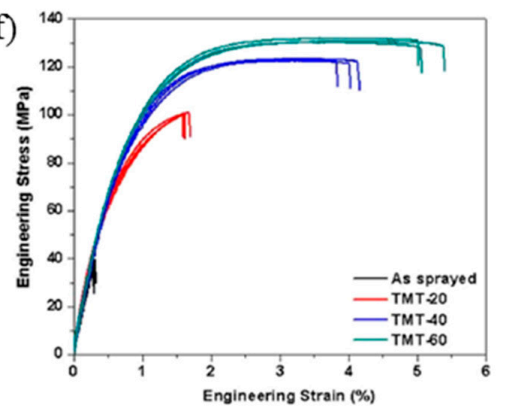

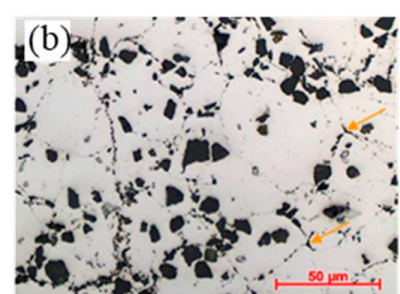
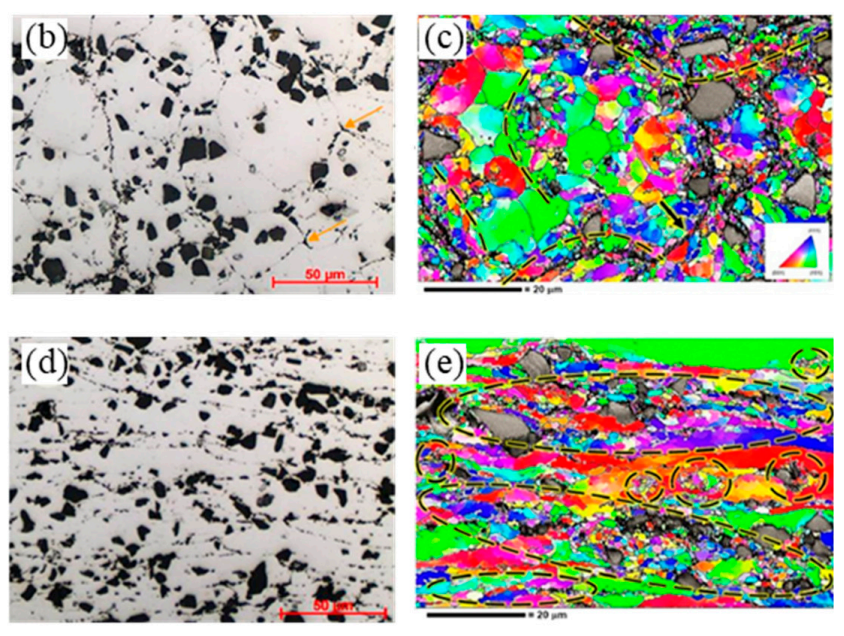

Figure 20. (a) Schematic diagram of hot rolling process, (b-e) optical micrographs and EBSD results of cross-sections for $(\mathbf{b}, \mathbf{c})$ as-sprayed and $(\mathbf{d}, \mathbf{e})$ hot-rolled samples, and (f) stress-strain plots of as-sprayed and hot-rolled samples (adapted from reference [88], with permission from (C Elsevier).

Another post process is a combination of hot rolling and hot compression (Figure 21a). Tariq et al. [90] demonstrated that this method was able to improve the mechanical properties of cold sprayed $\mathrm{B}_{4} \mathrm{C} / \mathrm{Al}$ MMCs. Similar to the hot rolling method, the thickness of the cold sprayed $\mathrm{B}_{4} \mathrm{C} / \mathrm{Al} \mathrm{MMC}$ deposits was reduced via hot compression treatment at $500^{\circ} \mathrm{C}$ followed by a hot rolling treatment, which could further deform the $\mathrm{Al}$ matrix and close the interconnected pores within the MMC deposits. At the same time, the bonding of $\mathrm{Al}-\mathrm{Al}$ and $\mathrm{Al}-\mathrm{B}_{4} \mathrm{C}$ interfaces was significantly enhanced and the $\mathrm{Al}$ grains were extensively refined due to the simultaneous operation of continuous dynamic recrystallization and geometric dynamic recrystallization mechanisms (Figure 21b-d) [90]. It was also found that this method could uniformly disperse $\mathrm{B}_{4} \mathrm{C}$ particles in the $\mathrm{Al}$ matrix, which resulted in a homogeneous distribution of plastic strain and the formation of closely spaced multiple intersecting shear bands in the matrix. Consequently, the ultimate tensile strength and elongation of the as-deposited samples were simultaneously improved from about $37 \mathrm{MPa}$ to $185 \mathrm{MPa}$ and from about $0.3 \%$ to $6.2 \%$, respectively 
(Figure 21e). In contrast to the isothermally heat-treated samples, this hybrid treatment resulted in about three-fold higher strength and four-fold higher elongation.
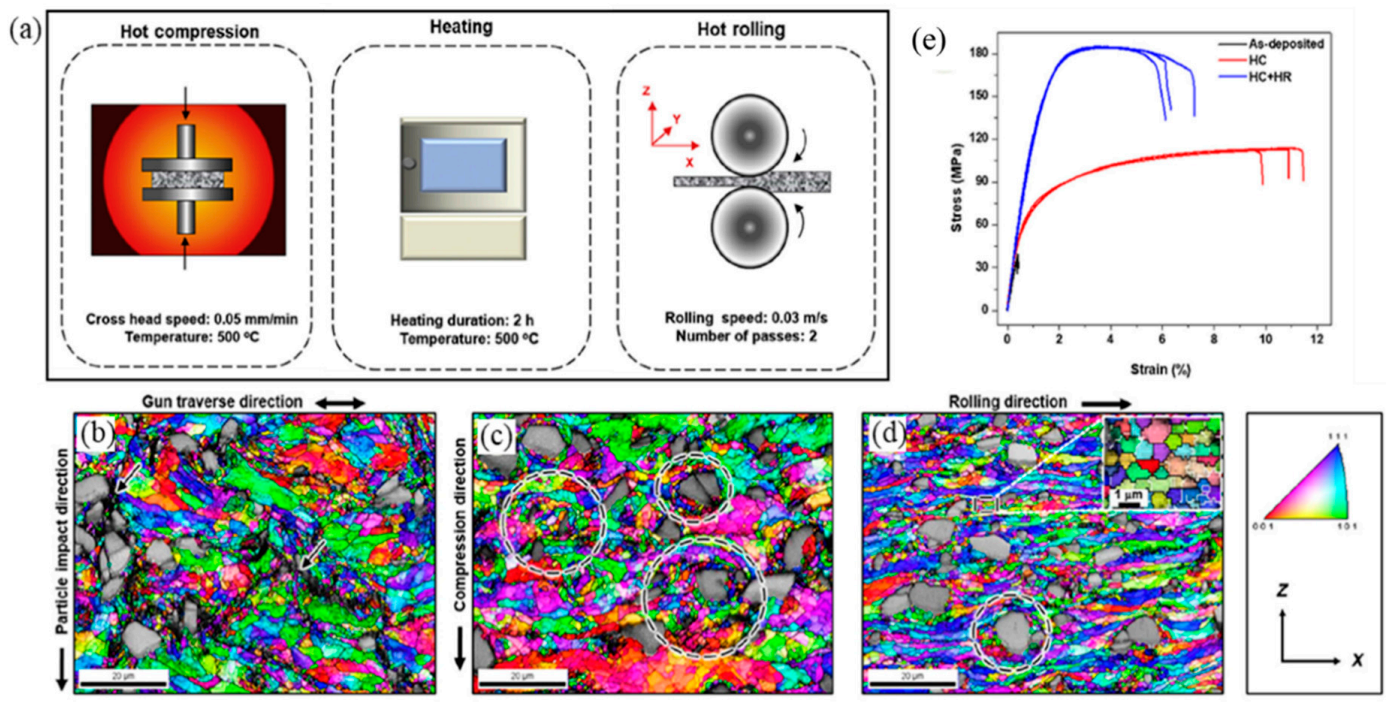

Figure 21. (a) Schematic illustrations of a hybrid post hot compression + hot rolling treatment, (b-d) IPF mappings of $\mathrm{Al} / \mathrm{B}_{4} \mathrm{C}$ samples processed under different conditions: (b) as-deposited, (c) after hot compression and (d) after hot compression + hot rolling, and (e) tensile stress-strain relationships of the corresponding $\mathrm{Al} / \mathrm{B}_{4} \mathrm{C}$ samples (adapted from reference [90], with permission from $\left.{ }^{(}\right)$Elsevier).

Surface finish turning and ball burnishing are two other post treatment methods that could modify the surface condition of cold sprayed deposits (Figure 22a). Courbon et al. [91] studied the effect of finish turning and ball-burnishing on cold sprayed 17-4PH stainless steel deposits. Applying a finish turning and ball-burnishing operation, the integrity of the coating remained without any crack, delamination or torn particles (Figure 22b-d) [91]. However, the operation affected the near-surface microstructure, resulting in a 5 to $10 \mu \mathrm{m}$ thick transformed layer in the deposits. The inter-particle boundaries of the cold sprayed coating were severely deformed with an orientation directed towards the material removal/deformation direction (Figure 22b-d). It was also found that severe plastic deformation induced by finish turning and ball-burnishing led to the activation of grain refinement due to an intense shear localization [91-94]. In addition, tensile residual stresses up to $150 \mathrm{MPa}$ were induced along the first 15 to $20 \mu \mathrm{m}$ in the both axial and tangential directions by the finish turning operation in the cold sprayed coatings followed by a compression state under about $-300 \mathrm{MPa}$ to a depth of around $40 \mu \mathrm{m}$ [91]. Ball-burnishing was able to change the residual stress profile left by the finish turning into a compressive one [91]. After ball-burnishing, the top surface displayed a residual stress of about $-50 \mathrm{MPa}$, which gradually decreased to around $-200 \mathrm{MPa}$ along the first $200 \mu \mathrm{m}$ in depth (Figure 22e). However, further investigation should be performed to expand the understanding of the microstructural evolution mechanism in the near surface region during surface finish turning and ball burnishing. 
(a)

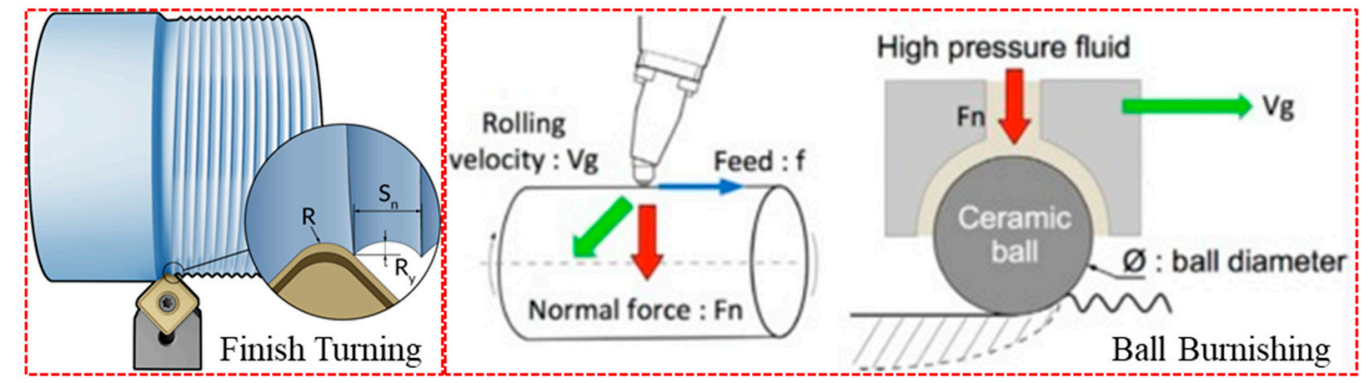

(b)

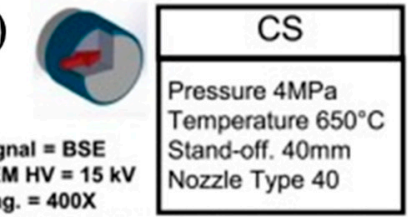

Mag. $=400 X$
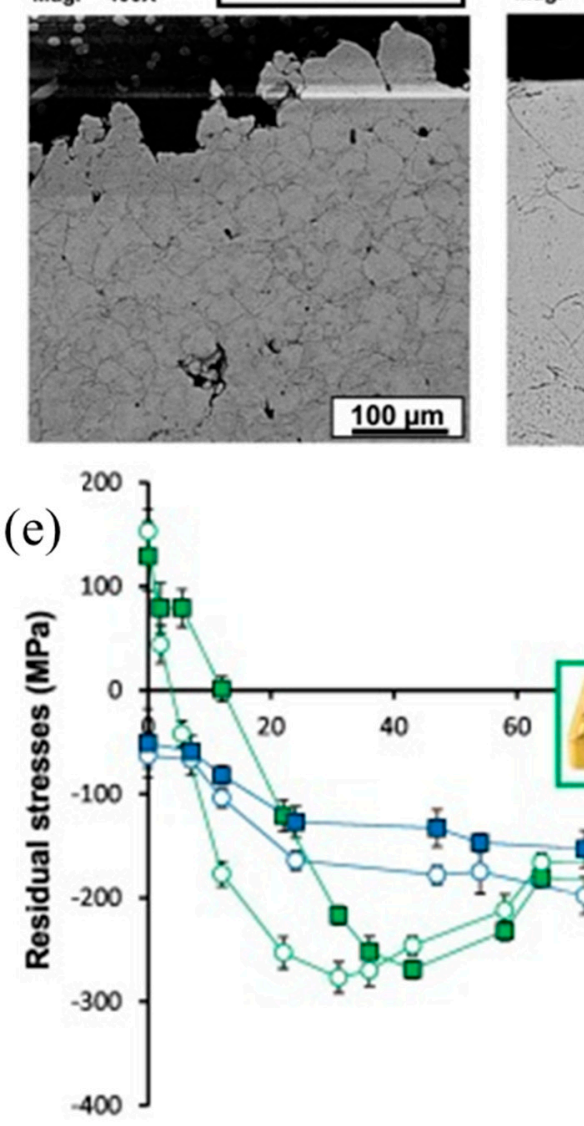

(c)

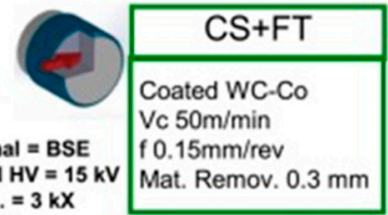

Mag. $=3 \mathrm{kX}$

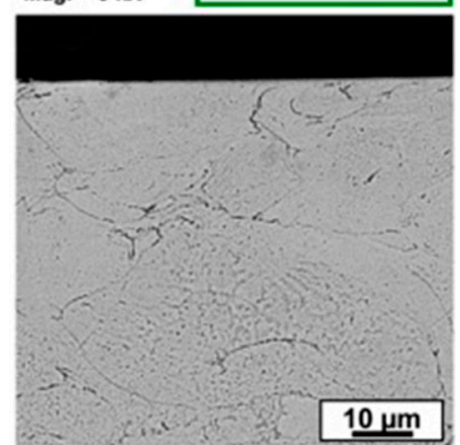

(d)

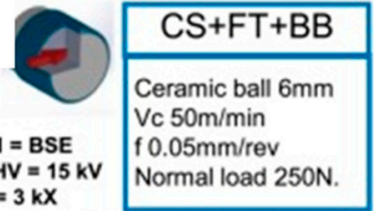

SEM HV $=15$

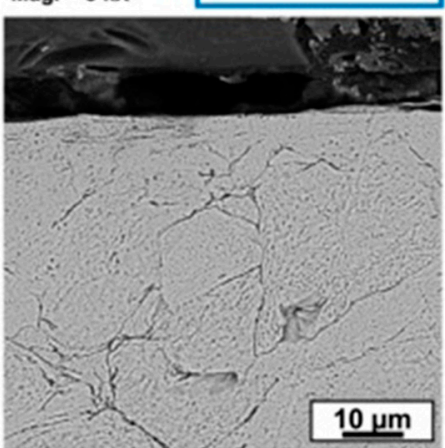

$10 \mu \mathrm{m}$

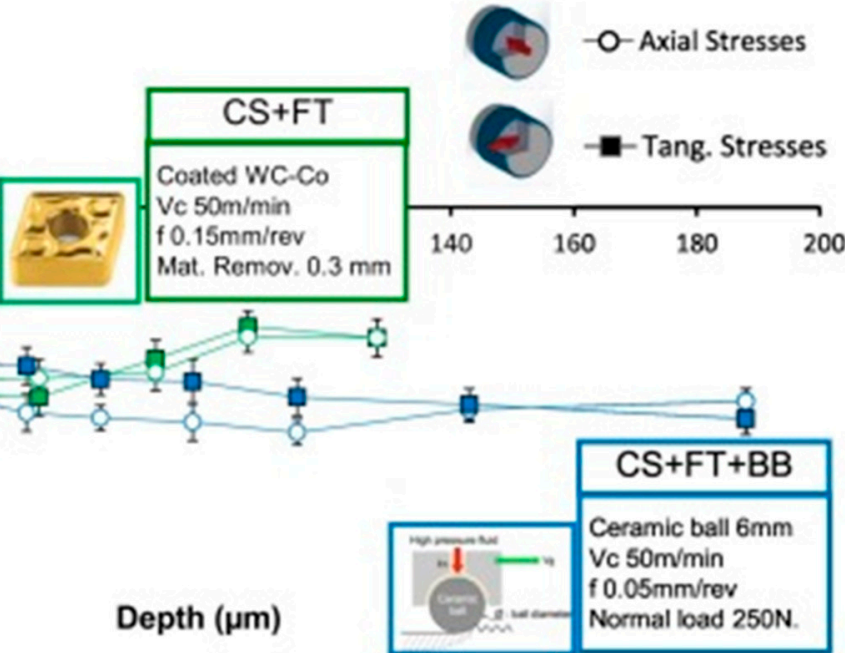

Figure 22. (a) Schematic diagram of finish turning and ball burnishing processes, (b-d) SEM images of (b) as-cold sprayed 17-4PH stainless steel coating, (c) cold sprayed 17-4PH stainless steel coating after finish turning, and (d) cold sprayed 17-4PH stainless steel coating after finish turning + ball burnishing; and (e) residual stress profiles of the cold sprayed 17-4PH stainless steel coating after finish turning (FT) and finish turning followed by ball-burnishing (BB) (adapted from reference [91], with permission from ${ }^{(C)}$ Elsevier).

In addition, hot isostatic pressing can also be employed as a post-process treatment method, which compresses materials by applying high temperature (up to $2000{ }^{\circ} \mathrm{C}$ ) and isostatic pressure (up to $200 \mathrm{MPa}$ ) at the same time. Chen et al. [95] adopted HIP treatment to reduce the interior defects, adjust the microstructure, and improve the mechanical properties of cold sprayed Ti6Al4V deposits. The optical microscopy images (Figure 23a-d) and 3D reconstructions by XCT (Figure 23e-h) showed that the fully dense Ti6Al4V deposits were obtained through the high temperature diffusion and 
high pressure compacting of the HIP samples. After HIP treatment, the severely deformed grains experienced an obvious growth with the uniformly distributed $\beta$ precipitates around the equiaxed $\alpha$ grains. The tensile test results showed that the strength as well as the elongation of the cold sprayed Ti6Al4V deposits could be largely improved by the enhanced diffusion and resultant metallurgical bonding (Figure 23i-j). With HIP treatment, the cold sprayed samples exhibited highly densified morphology and improved microstructure that could benefit the improvement of mechanical properties. Petrovskiy et al. [96] observed similar improvement of cold sprayed Ti deposits using HIP. The results showed that HIP at $110 \mathrm{MPa}$ and $900{ }^{\circ} \mathrm{C}$ significantly changed the microstructure of the cold sprayed Ti deposits. Total porosity in the Ti deposits was decreased from $4.3 \%$ to $2.2 \%$ due to elimination of small-scale porosity, whereas larger pores were not completely closed. The ultimate tensile strength of the as-sprayed and HIP-treated samples was 110 and $480 \mathrm{MPa}$, respectively, which was due to material diffusion and microstructure changes during the HIP. At the same time, the elongation of the samples after the HIP treatment was only $\sim 8 \%$, which was significantly lower than that for the bulk pure titanium. Yin et al. [26] compared the effects of HIP and vacuum annealing on the microstructure and mechanical properties of cold sprayed 316L stainless steel deposits. The results showed that although the deposit porosity was significantly reduced after HIP, the mechanical properties of the deposits did not surpass the vacuum-annealed samples. It was reported that this was probably caused by the original oxide films retained at the particle surfaces in the original inter-particle pore areas, which hindered the intimate metallurgical inter-particle bonding.

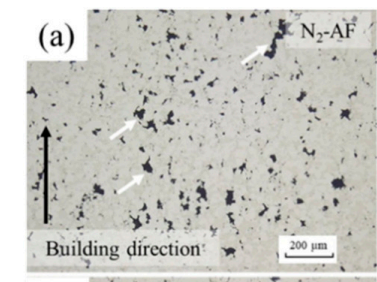

(c)

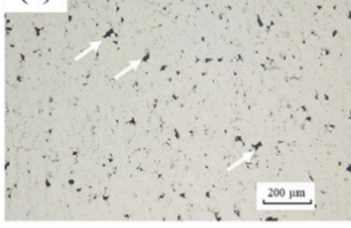

(i)

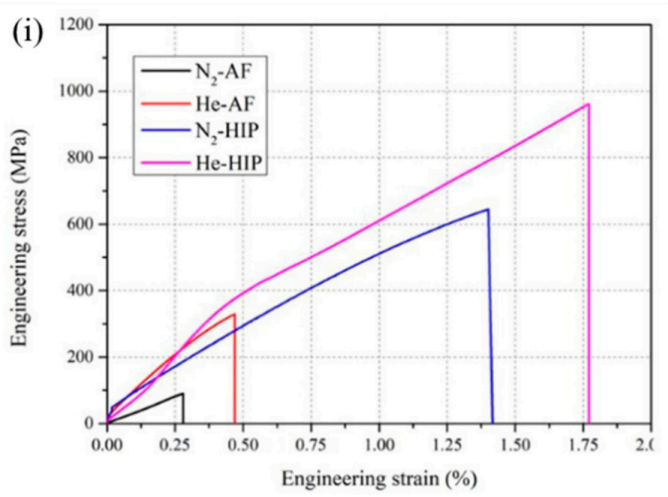

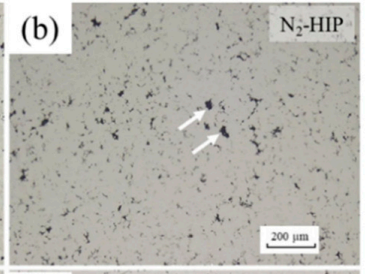

(d)

He-HIP

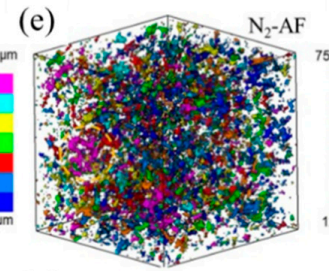

(g)
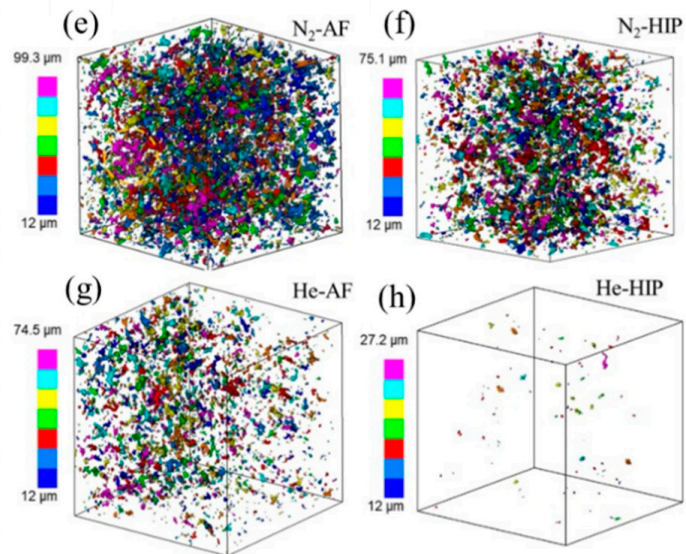

(j)

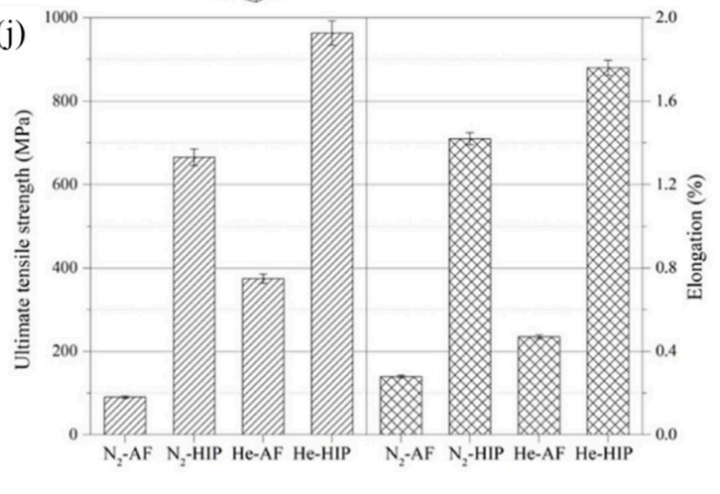

Figure 23. (a-d) Optical images of the cross-sections of cold sprayed Ti6Al4V samples treated under different conditions: (a) as-cold sprayed by using $\mathrm{N}_{2}$ and (b) after HIP; (c) as-cold sprayed by using He and (d) after HIP; (e-h) 3D-reconstructions of the pores within the cold sprayed Ti6Al4V samples treated under different conditions: (e) $\mathrm{N}_{2}-\mathrm{AF}$; (f) $\mathrm{N}_{2}-\mathrm{HIP}$; (g) He-AF; and (h) He-HIP; (i) tensile stress-strain relationships and $(\mathbf{j})$ ultimate tensile strengths of cold sprayed Ti6Al4V samples treated under the respective conditions (adapted from reference [95], with permission from ${ }^{\complement}$ Elsevier). 
Table 6. Effect of other post treatments on cold sprayed coatings.

\begin{tabular}{|c|c|c|c|c|}
\hline Coatings & References & Post Process & Parameters & Main Findings \\
\hline $\mathrm{B}_{4} \mathrm{C} / \mathrm{Al}$ & [88] & Hot rolling & $\begin{array}{l}\text { Heating: } ~ 500{ }^{\circ} \mathrm{C} \text { for } 2 \mathrm{~h} \\
\text { Rolling: unidirectional at a rolling } \\
\text { speed of } 0.03 \mathrm{~m} / \mathrm{s}\end{array}$ & $\begin{array}{l}\text { After hot rolling, recrystallized grains and sub-structured } \\
\text { grains were formed in the coatings. The tensile strength and } \\
\text { elongation of the rolled coatings were much higher than those } \\
\text { of the as-sprayed and conventionally heat-treated coatings. }\end{array}$ \\
\hline $\mathrm{Si} / \mathrm{A} 380$ & [89] & Hot rolling & $\begin{array}{l}\text { Heating: } \sim 500^{\circ} \mathrm{C} \text { for } 2 \mathrm{~h} \\
\text { Rolling: unidirectional at a rolling } \\
\text { speed of } 0.03 \mathrm{~m} / \mathrm{s}\end{array}$ & $\begin{array}{l}\text { After hot rolling, the reinforcement Si particles were refined } \\
\text { and uniformly distributed in the Al matrix. The UTS and } \\
\text { elongation of the rolled coatings were significantly improved } \\
\text { compared to those of the as-sprayed and conventionally } \\
\text { heat-treated coatings. }\end{array}$ \\
\hline $\mathrm{B}_{4} \mathrm{C} / \mathrm{Al}$ & [90] & $\begin{array}{l}\text { Hot compression }+ \\
\text { Hot rolling }\end{array}$ & $\begin{array}{l}\text { Hot compression: } \sim 50{ }^{\circ} \mathrm{C} \text { with speed } \\
\text { of } 0.05 \mathrm{~mm} / \mathrm{min} \\
\text { Hot rolling: } \sim 500^{\circ} \mathrm{C} \text { for } 2 \mathrm{~h} \text {, followed } \\
\text { by rolling speed at } 0.03 \mathrm{~m} / \mathrm{s} \text {. }\end{array}$ & $\begin{array}{l}\text { After the hybrid treatment, the } \mathrm{Al} \text { grains were extensively } \\
\text { refined and the } \mathrm{B}_{4} \mathrm{C} \text { particles were homogeneously } \\
\text { distributed in the matrix. The tensile strength and elongation } \\
\text { of the coatings were simultaneously improved. }\end{array}$ \\
\hline $\begin{array}{l}\text { 17-4PH stainless } \\
\text { steel }\end{array}$ & [91] & $\begin{array}{l}\text { Finish turning and } \\
\text { ball-burnishing }\end{array}$ & $\begin{array}{l}\text { Finish turning: tungsten carbide tool, } \\
\text { cutting speed ( } 50 \mathrm{~m} / \mathrm{min}) \text {, feed rate } \\
(0.15 \mathrm{~mm} / \mathrm{rev}) \text {, depth of cut }(0.3 \mathrm{~mm}) \text {. } \\
\text { Ball-burnishing: ceramic ball }(6 \mathrm{~mm} \\
\text { diameter), feed ( } 0.05 \mathrm{~mm} / \mathrm{rev}) \text {, speed } \\
(50 \mathrm{~m} / \mathrm{min}) \text { and load }(250 \mathrm{~N})\end{array}$ & $\begin{array}{l}\text { Applying finish turning or ball-burnishing operation affected } \\
\text { the near-surface microstructure, resulting in a transformed } \\
\text { layer in the coatings. After finish turning, tensile residual } \\
\text { stresses were induced at the coating surface. After } \\
\text { ball-burnishing, the surface tensile stresses were turned into } \\
\text { compressive residual ones. }\end{array}$ \\
\hline Ti64 & [95] & HIP & $\begin{array}{l}\text { Temperature: } 920^{\circ} \mathrm{C} \\
\text { Pressure: } 120 \mathrm{MPa} \\
\text { Duration: } 2 \mathrm{~h} \\
\text { Gas: Ar }\end{array}$ & $\begin{array}{l}\text { After HIP, the coating porosity was significantly reduced, and } \\
\text { the tensile strength of the coatings increased from } 150 \mathrm{MPa} \text { to } \\
650 \mathrm{MPa} \text {. }\end{array}$ \\
\hline Pure Ti & [96] & HIP & $\begin{array}{l}\text { Temperature: } 900{ }^{\circ} \mathrm{C} \\
\text { Pressure: } 110 \mathrm{MPa} \\
\text { Gas: } \mathrm{Ar}\end{array}$ & $\begin{array}{l}\text { After HIP, the coating porosity was decreased from } 4.3 \text { to } 2.2 \% \\
\text { and the UTS of the coatings was increased from } 110 \text { to } 480 \\
\text { MPa. }\end{array}$ \\
\hline $316 \mathrm{~L}$ & [26] & HIP & $\begin{array}{l}\text { Temperature: } 1000^{\circ} \mathrm{C} \\
\text { Pressure: } 150 \mathrm{MPa} \\
\text { Gas: Ar } \\
\text { Duration: } 4 \mathrm{~h}\end{array}$ & $\begin{array}{l}\text { After HIP, the coating porosity was significantly decreased } \\
\text { and the UTS of the coatings was increased. However, the } \\
\text { mechanical properties of HIPed samples did not surpass } \\
\text { those of the vacuum-annealed samples. }\end{array}$ \\
\hline
\end{tabular}




\section{Summary and Outlook}

Metal cold spray process has been rapidly developed in recent years, not only in fundamental research but also in a wide range of applications. By virtue of its high kinetic energy, low heat input and rapid buildup rate, cold spray has immense potential as a commercially viable industrial manufacturing process.

However, due to the bonding nature of cold spray deposition, there are some inevitable defects in as-sprayed deposits. Applying post-process treatments to cold sprayed deposits can reduce the number of defects and improve the mechanical properties of the deposits. Remarkable progress has been made in post treatments of cold sprayed deposits, which include heat treatment, friction-stir processing, shot peening, laser re-melting, and many others.

Heat treatment is usually employed to enhance atomic diffusion between splat/splat and deposit/substrate, leading to better ductility, higher cohesive strength as well as higher adhesive strength of cold sprayed deposits. However, heat treatment usually results in unfavored grain growth and phase change in the deposits.

Friction-stir processing is beneficial for compacting cold sprayed coatings and improving the cohesive strength of the coatings. However, friction-stir processing induces a heat affect zone and thus affecting the coating integrity.

Shot peening can compact the coating surfaces and induce compressive stresses in cold sprayed coatings, but it should be performed with caution not to damage the coating surface.

Laser re-melting can densify the top layer of cold sprayed coatings, which is beneficial for wear and corrosion protection. However, there exist big pores between the re-melted layer and the base material, which deserves more fundamental research.

Other post-process treatments, such as hot rolling, hot compressing and hot isostatic pressing, are also capable of improving the quality of cold sprayed deposits, which need comprehensive investigations of their optimal process parameters.

The post-process treatments can provide excellent opportunities for cold-sprayed deposits to qualify industry's requirements for them.

Author Contributions: Conceptualization, W.S. and E.L.; Methodology, W.S.; Investigation, W.S., A.W.-Y.T. and K.W.; Writing-Original, Draft Preparation, W.S.; Writing—Review and Editing, W.S., A.W.-Y.T., K.W., S.Y., X.Y. and E.L.; Supervision, E.L.; Project Administration, E.L. and I.M. All authors have read and agreed to the published version of the manuscript.

Funding: This work was financially supported by Industry Alignment Fund (IAF) of Singapore A*STAR, Rolls-Royce (RR), and Nanyang Technological University (NTU), Singapore, with the research grant number: ARMS 1.1 Advanced Metallized Coatings using Cold Spray.

Acknowledgments: Authors would like to thank Singapore A*STAR, Rolls-Royce and Nanyang Technological University.

Conflicts of Interest: The authors declare no conflict of interest.

\section{References}

1. Yin, S.; Cavaliere, P.; Aldwell, B.; Jenkins, R.; Liao, H.; Li, W.; Lupoi, R. Cold spray additive manufacturing and repair: Fundamentals and applications. Addit. Manuf. 2018, 21, 628-650. [CrossRef]

2. Papyrin, A.; Kosarev, V.; Klinkov, S.; Alkhimov, A.; Fomin, V.M. Cold Spray Technology; Elsevier: Amsterdam, The Netherlands, 2006.

3. Assadi, H.; Gärtner, F.; Stoltenhoff, T.; Kreye, H. Bonding mechanism in cold gas spraying. Acta Mater. 2003, 51, 4379-4394. [CrossRef]

4. Villafuerte, J. Modern Cold Spray: Materials, Process, and Applications; Springer: Berlin, Germany, 2015.

5. Assadi, H.; Kreye, H.; Gärtner, F.; Klassen, T. Cold spraying-A materials perspective. Acta Mater. 2016, 116, 382-407. [CrossRef]

6. Moridi, A.; Hassani-Gangaraj, S.M.; Guagliano, M.; Dao, M. Cold spray coating: Review of material systems and future perspectives. Surf. Eng. 2014, 30, 369-395. [CrossRef] 
7. An, S.; Joshi, B.; Yarin, A.L.; Swihart, M.T.; Yoon, S.S. Supersonic Cold Spraying for Energy and Environmental Applications: One-Step Scalable Coating Technology for Advanced Micro- and Nanotextured Materials. Adv. Mater. 2020, 32, 1905028. [CrossRef]

8. Champagne, V.K. The Cold Spray Materials Deposition Process; Elsevier: Amsterdam, The Netherlands, 2007.

9. Ichikawa, Y.; Tokoro, R.; Tanno, M.; Ogawa, K. Elucidation of cold-spray deposition mechanism by auger electron spectroscopic evaluation of bonding interface oxide film. Acta Mater. 2019, 164, 39-49. [CrossRef]

10. Hassani-Gangaraj, M.; Veysset, D.; Champagne, V.K.; Nelson, K.A.; Schuh, C.A. Adiabatic shear instability is not necessary for adhesion in cold spray. Acta Mater. 2018, 158, 430-439. [CrossRef]

11. Champagne, V.; Helfritch, D.; Leyman, P.; Lempicki, R.; Grendahl, S. The effects of gas and metal characteristics on sprayed metal coatings. Model. Simul. Mater. Sci. Eng. 2005, 13, 1119-1128. [CrossRef]

12. Champagne, V.K.; West, M.K.; Reza Rokni, M.; Curtis, T.; Champagne, V.; McNally, B. Joining of Cast ZE41A Mg to Wrought $6061 \mathrm{Al}$ by the Cold Spray Process and Friction Stir Welding. J. Therm. Spray Technol. 2015, 25, 143-159. [CrossRef]

13. Sun, W.; Tan, A.W.Y.; Marinescu, I.; Toh, W.Q.; Liu, E. Adhesion, tribological and corrosion properties of cold-sprayed CoCrMo and Ti6Al4V coatings on 6061-T651 Al alloy. Surf. Coat. Technol. 2017, 326, 291-298. [CrossRef]

14. Champagne, V.K.; Helfritch, D.; Leyman, P.; Grendahl, S.; Klotz, B. Interface Material Mixing Formed by the Deposition of Copper on Aluminum by Means of the Cold Spray Process. J. Therm. Spray Technol. 2005, 14, 330-334. [CrossRef]

15. Ko, K.H.; Choi, J.O.; Lee, H. Intermixing and interfacial morphology of cold-sprayed Al coatings on steel. Mater. Lett. 2014, 136, 45-47. [CrossRef]

16. Bae, G.; Kumar, S.; Yoon, S.; Kang, K.; Na, H.; Kim, H.-J.; Lee, C. Bonding features and associated mechanisms in kinetic sprayed titanium coatings. Acta Mater. 2009, 57, 5654-5666. [CrossRef]

17. Guetta, S.; Berger, M.H.; Borit, F.; Guipont, V.; Jeandin, M.; Boustie, M.; Ichikawa, Y.; Sakaguchi, K.; Ogawa, K. Influence of Particle Velocity on Adhesion of Cold-Sprayed Splats. J. Therm. Spray Technol. 2009, 18, 331-342. [CrossRef]

18. Barmouz, M.; Givi, M.K.B. Fabrication of in situ Cu/SiC composites using multi-pass friction stir processing: Evaluation of microstructural, porosity, mechanical and electrical behavior. Compos. Part A Appl. Sci. Manuf. 2011, 42, 1445-1453. [CrossRef]

19. Luzin, V.; Spencer, K.; Zhang, M.X. Residual stress and thermo-mechanical properties of cold spray metal coatings. Acta Mater. 2011, 59, 1259-1270. [CrossRef]

20. Saleh, M.; Luzin, V.; Spencer, K. Analysis of the residual stress and bonding mechanism in the cold spray technique using experimental and numerical methods. Surf. Coat. Technol. 2014, 252, 15-28. [CrossRef]

21. Spencer, K.; Luzin, V.; Matthews, N.; Zhang, M.X. Residual stresses in cold spray Al coatings: The effect of alloying and of process parameters. Surf. Coat. Technol. 2012, 206, 4249-4255. [CrossRef]

22. Boruah, D.; Ahmad, B.; Lee, T.L.; Kabra, S.; Syed, A.K.; McNutt, P.; Doré, M.; Zhang, X. Evaluation of residual stresses induced by cold spraying of Ti-6Al-4V on Ti-6Al-4V substrates. Surf. Coat. Technol. 2019, 374, 591-602. [CrossRef]

23. Spencer, K.; Zhang, M.X. Heat treatment of cold spray coatings to form protective intermetallic layers. Scr. Mater. 2009, 61, 44-47. [CrossRef]

24. Sudharshan Phani, P.; Srinivasa Rao, D.; Joshi, S.V.; Sundararajan, G. Effect of Process Parameters and Heat Treatments on Properties of Cold Sprayed Copper Coatings. J. Therm. Spray Technol. 2007, 16, 425-434. [CrossRef]

25. Kumar, S.; Jyothirmayi, A.; Wasekar, N.; Joshi, S.V. Influence of annealing on mechanical and electrochemical properties of cold sprayed niobium coatings. Surf. Coat. Technol. 2016, 296, 124-135. [CrossRef]

26. Yin, S.; Cizek, J.; Yan, X.; Lupoi, R. Annealing strategies for enhancing mechanical properties of additively manufactured 316L stainless steel deposited by cold spray. Surf. Coat. Technol. 2019, 370, 353-361. [CrossRef]

27. Yu, J.S.; Kim, H.J.; Oh, I.H.; Lee, K.A. Densification and Purification of Cold Sprayed Ti Coating Layer by Using Annealing in Different Heat Treatment Environments. Adv. Mater. Res. 2012, 602-604, 1604-1608. [CrossRef]

28. Huang, R.; Sone, M.; Ma, W.; Fukanuma, H. The effects of heat treatment on the mechanical properties of cold-sprayed coatings. Surf. Coat. Technol. 2015, 261, 278-288. [CrossRef] 
29. Yang, K.; Li, W.; Yang, X.; Xu, Y.; Vairis, A. Effect of heat treatment on the inherent anisotropy of cold sprayed copper deposits. Surf. Coat. Technol. 2018, 350, 519-530. [CrossRef]

30. Li, W.Y.; Guo, X.P.; Verdy, C.; Dembinski, L.; Liao, H.L.; Coddet, C. Improvement of microstructure and property of cold-sprayed $\mathrm{Cu}-4$ at.\%Cr-2at.\%Nb alloy by heat treatment. Scr. Mater. 2006, 55, 327-330. [CrossRef]

31. Rokni, M.R.; Widener, C.A.; Champagne, V.K.; Crawford, G.A. Microstructure and mechanical properties of cold sprayed 7075 deposition during non-isothermal annealing. Surf. Coat. Technol. 2015, 276, 305-315. [CrossRef]

32. Lee, H.Y.; Jung, S.H.; Lee, S.Y.; Ko, K.H. Fabrication of cold sprayed Al-intermetallic compounds coatings by post annealing. Mater. Sci. Eng. A 2006, 433, 139-143. [CrossRef]

33. Yang, G.-J.; Wang, H.-T.; Li, C.-J.; Li, C.-X. Effect of annealing on the microstructure and erosion performance of cold-sprayed FeAl intermetallic coatings. Surf. Coat. Technol. 2011, 205, 5502-5509. [CrossRef]

34. Meng, X.-M.; Zhang, J.-B.; Han, W.; Zhao, J.; Liang, Y.-L. Influence of annealing treatment on the microstructure and mechanical performance of cold sprayed 304 stainless steel coating. Appl. Surf. Sci. 2011, 258, 700-704. [CrossRef]

35. Ren, Y.Q.; King, P.C.; Yang, Y.S.; Xiao, T.Q.; Chu, C.; Gulizia, S.; Murphy, A.B. Characterization of heat treatment-induced pore structure changes in cold-sprayed titanium. Mater. Charact. 2017, 132, 69-75. [CrossRef]

36. Tang, J.; Saha, G.C.; Richter, P.; Kondás, J.; Colella, A.; Matteazzi, P. Effects of Post-spray Heat Treatment on Hardness and Wear Properties of Ti-WC High-Pressure Cold Spray Coatings. J. Therm. Spray Technol. 2018, 27, 1153-1164. [CrossRef]

37. Sun, W.; Bhowmik, A.; Tan, A.W.-Y.; Li, R.; Xue, F.; Marinescu, I.; Liu, E. Improving microstructural and mechanical characteristics of cold-sprayed Inconel 718 deposits via local induction heat treatment. J. Alloys Compd. 2019, 797, 1268-1279. [CrossRef]

38. Ma, W.; Xie, Y.; Chen, C.; Fukanuma, H.; Wang, J.; Ren, Z.; Huang, R. Microstructural and mechanical properties of high-performance Inconel 718 alloy by cold spraying. J. Alloys Compd. 2019, 792, 456-467. [CrossRef]

39. Wong, W.; Irissou, E.; Vo, P.; Sone, M.; Bernier, F.; Legoux, J.G.; Fukanuma, H.; Yue, S. Cold Spray Forming of Inconel 718. J. Therm. Spray Technol. 2012, 22, 413-421. [CrossRef]

40. Xie, X.; Chen, C.; Ma, Y.; Xie, Y.; Wu, H.; Ji, G.; Aubry, E.; Ren, Z.; Liao, H. Influence of annealing treatment on microstructure and magnetic properties of cold sprayed Ni-coated FeSiAl soft magnetic composite coating. Surf. Coat. Technol. 2019, 374, 476-484. [CrossRef]

41. Eason, P.D.; Fewkes, J.A.; Kennett, S.C.; Eden, T.J.; Tello, K.; Kaufman, M.J.; Tiryakioğlu, M. On the characterization of bulk copper produced by cold gas dynamic spray processing in as fabricated and annealed conditions. Mater. Sci. Eng. A 2011, 528, 8174-8178. [CrossRef]

42. Khun, N.W.; Tan, A.W.Y.; Sun, W.; Liu, E. Effect of Heat Treatment Temperature on Microstructure and Mechanical and Tribological Properties of Cold Sprayed Ti-6Al-4V Coatings. Tribol. Trans. 2016, 60, 1033-1042. [CrossRef]

43. Tan, A.W.-Y.; Sun, W.; Phang, Y.P.; Dai, M.; Marinescu, I.; Dong, Z.; Liu, E. Effects of Traverse Scanning Speed of Spray Nozzle on the Microstructure and Mechanical Properties of Cold-Sprayed Ti6Al4V Coatings. J. Therm. Spray Technol. 2017, 26, 1484-1497. [CrossRef]

44. Tan, A.; Lek, J.; Sun, W.; Bhowmik, A.; Marinescu, I.; Song, X.; Zhai, W.; Li, F.; Dong, Z.; Boothroyd, C.; et al. Influence of Particle Velocity When Propelled Using N2 or N2-He Mixed Gas on the Properties of Cold-Sprayed Ti6Al4V Coatings. Coatings 2018, 8, 327. [CrossRef]

45. Sun, W.; Tan, A.W.Y.; Bhowmik, A.; Marinescu, I.; Song, X.; Zhai, W.; Li, F.; Liu, E. Deposition characteristics of cold sprayed Inconel 718 particles on Inconel 718 substrates with different surface conditions. Mater. Sci. Eng. A 2018, 720, 75-84. [CrossRef]

46. Khun, N.W.; Tan, A.W.Y.; Sun, W.; Liu, E. Wear and Corrosion Resistance of Thick Ti-6Al-4V Coating Deposited on Ti-6Al-4V Substrate via High-Pressure Cold Spray. J. Therm. Spray Technol. 2017, 26, 1393-1407. [CrossRef]

47. Song, X.; Everaerts, J.; Zhai, W.; Zheng, H.; Tan, A.W.Y.; Sun, W.; Li, F.; Marinescu, I.; Liu, E.; Korsunsky, A.M. Residual stresses in single particle splat of metal cold spray process-Numerical simulation and direct measurement. Mater. Lett. 2018, 230, 152-156. [CrossRef] 
48. Li, W.Y.; Zhang, C.; Liao, H.; Coddet, C. Effect of heat treatment on microstructure and mechanical properties of cold sprayed Ti coatings with relatively large powder particles. J. Coat. Technol. Res. 2008, 6, 401-406. [CrossRef]

49. Tan, A.W.-Y.; Sun, W.; Bhowmik, A.; Lek, J.Y.; Marinescu, I.; Li, F.; Khun, N.W.; Dong, Z.; Liu, E. Effect of coating thickness on microstructure, mechanical properties and fracture behaviour of cold sprayed Ti6Al4V coatings on Ti6Al4V substrates. Surf. Coat. Technol. 2018, 349, 303-317. [CrossRef]

50. Tan, A.W.-Y.; Sun, W.; Bhowmik, A.; Lek, J.Y.; Song, X.; Zhai, W.; Zheng, H.; Li, F.; Marinescu, I.; Dong, Z.; et al. Effect of Substrate Surface Roughness on Microstructure and Mechanical Properties of Cold-Sprayed Ti6Al4V Coatings on Ti6Al4V Substrates. J. Therm. Spray Technol. 2019, 28, 1959-1973. [CrossRef]

51. Yin, S.; Wang, X.; Li, W.; Liao, H.; Jie, H. Deformation behavior of the oxide film on the surface of cold sprayed powder particle. Appl. Surf. Sci. 2012, 259, 294-300. [CrossRef]

52. Wang, H.-T.; Li, C.-J.; Yang, G.-J.; Li, C.-X. Effect of heat treatment on the microstructure and property of cold-sprayed nanostructured $\mathrm{FeAl} / \mathrm{Al}_{2} \mathrm{O}_{3}$ intermetallic composite coating. Vacuum 2008, 83, 146-152. [CrossRef]

53. Wang, H.-T.; Li, C.-J.; Yang, G.-J.; Li, C.-X. Cold spraying of Fe/Al powder mixture: Coating characteristics and influence of heat treatment on the phase structure. Appl. Surf. Sci. 2008, 255, 2538-2544. [CrossRef]

54. Bobzin, K.; Öte, M.; Wiesner, S.; Gerdt, L. Investigation of the interfacial reactions between steel and aluminum coatings for hybrid casting. IOP Conf. Ser. Mater. Sci. Eng. 2018, 373, 012013. [CrossRef]

55. Maev, R.; Leshchynsky, V. Cold Gas Dynamic Spray; Taylor \& Francis: Abingdon, UK, 2015.

56. Peat, T.; Galloway, A.; Toumpis, A.; McNutt, P.; Iqbal, N. The erosion performance of cold spray deposited metal matrix composite coatings with subsequent friction stir processing. Appl. Surf. Sci. 2017, 396, 1635-1648. [CrossRef]

57. Peat, T.; Galloway, A.; Toumpis, A.; Steel, R.; Zhu, W.; Iqbal, N. Enhanced erosion performance of cold spray co-deposited AISI316 MMCs modified by friction stir processing. Mater. Des. 2017, 120, 22-35. [CrossRef]

58. Huang, C.; Li, W.; Zhang, Z.; Planche, M.-p.; Liao, H.; Montavon, G. Effect of Tool Rotation Speed on Microstructure and Microhardness of Friction-Stir-Processed Cold-Sprayed SiCp/Al5056 Composite Coating. J. Therm. Spray Technol. 2016, 25, 1357-1364. [CrossRef]

59. Huang, C.; Li, W.; Feng, Y.; Xie, Y.; Planche, M.-P.; Liao, H.; Montavon, G. Microstructural evolution and mechanical properties enhancement of a cold-sprayed $\mathrm{Cu} \mathrm{Zn}$ alloy coating with friction stir processing. Mater. Charact. 2017, 125, 76-82. [CrossRef]

60. Khodabakhshi, F.; Marzbanrad, B.; Shah, L.H.; Jahed, H.; Gerlich, A.P. Friction-stir processing of a cold sprayed AA7075 coating layer on the AZ31B substrate: Structural homogeneity, microstructures and hardness. Surf. Coat. Technol. 2017, 331, 116-128. [CrossRef]

61. Yang, K.; Li, W.; Huang, C.; Yang, X.; Xu, Y. Optimization of cold-sprayed $\mathrm{AA} 2024 / \mathrm{Al}_{2} \mathrm{O}_{3}$ metal matrix composites via friction stir processing: Effect of rotation speeds. J. Mater. Sci. Technol. 2018, 34, 2167-2177. [CrossRef]

62. Yang, K.; Li, W.; Xu, Y.; Yang, X. Using friction stir processing to augment corrosion resistance of cold sprayed AA2024/ $\mathrm{Al}_{2} \mathrm{O}_{3}$ composite coatings. J. Alloys Compd. 2019, 774, 1223-1232. [CrossRef]

63. Khodabakhshi, F.; Marzbanrad, B.; Jahed, H.; Gerlich, A.P. Interfacial bonding mechanisms between aluminum and titanium during cold gas spraying followed by friction-stir modification. Appl. Surf. Sci. 2018, 462, 739-752. [CrossRef]

64. Huang, C.J.; Yan, X.C.; Li, W.Y.; Wang, W.B.; Verdy, C.; Planche, M.P.; Liao, H.L.; Montavon, G. Post-spray modification of cold-sprayed $\mathrm{Ni}$-Ti coatings by high-temperature vacuum annealing and friction stir processing. Appl. Surf. Sci. 2018, 451, 56-66. [CrossRef]

65. Huang, C.; Li, W.; Zhang, Z.; Fu, M.; Planche, M.-p.; Liao, H.; Montavon, G. Modification of a cold sprayed $\mathrm{SiC}_{\mathrm{p}} / \mathrm{Al} 5056$ composite coating by friction stir processing. Surf. Coat. Technol. 2016, 296, 69-75. [CrossRef]

66. Hodder, K.J.; Izadi, H.; McDonald, A.G.; Gerlich, A.P. Fabrication of aluminum-alumina metal matrix composites via cold gas dynamic spraying at low pressure followed by friction stir processing. Mater. Sci. Eng. A 2012, 556, 114-121. [CrossRef]

67. Luzin, V.; Spencer, K.; Zhang, M.; Matthews, N.; Davis, J.; Saleh, M. Residual Stresses in Cold Spray Coatings. In Cold-Spray Coatings: Recent Trends and Future Perspectives; Cavaliere, P., Ed.; Springer International Publishing: Cham, Switzerland, 2018; pp. 451-480. 
68. Boruah, D.; Zhang, X.; Doré, M. Theoretical prediction of residual stresses induced by cold spray with experimental validation. Multidiscip. Modeling Mater. Struct. 2019, 15, 599-616. [CrossRef]

69. Gulizia, S.; Trentin, A.; Vezzù, S.; Rech, S.; King, P.; Jahedi, M.Z.; Guagliano, M. Characterisation of cold spray titanium coatings. Mater. Sci. Forum 2010, 654, 898-901. [CrossRef]

70. Phan, T.D.; Masood, S.H.; Jahedi, M.Z.; Zahiri, S.H. Residual stresses in cold spray process using finite element analysis. Mater. Sci. Forum 2010, 654, 1642-1645. [CrossRef]

71. Ghelichi, R.; Bagherifard, S.; Parienete, I.F.; Guagliano, M.; Vezzù, S. Experimental study of shot peening followed by cold spray coating on residual stresses of the treated parts. Struct. Durab. Health Monit. 2010, 6, 17-29.

72. Moridi, A.; Hassani-Gangaraj, S.M.; Vezzú, S.; Trško, L.; Guagliano, M. Fatigue behavior of cold spray coatings: The effect of conventional and severe shot peening as pre-/post-treatment. Surf. Coat. Technol. 2015, 283, 247-254. [CrossRef]

73. Zhang, Q.; Li, C.-J.; Li, C.-X.; Yang, G.-J.; Lui, S.-C. Study of oxidation behavior of nanostructured NiCrAlY bond coatings deposited by cold spraying. Surf. Coat. Technol. 2008, 202, 3378-3384. [CrossRef]

74. Zou, Y.; Qin, W.; Irissou, E.; Legoux, J.-G.; Yue, S.; Szpunar, J.A. Dynamic recrystallization in the particle/particle interfacial region of cold-sprayed nickel coating: Electron backscatter diffraction characterization. Scr. Mater. 2009, 61, 899-902. [CrossRef]

75. Sun, W.; Tan, A.W.-Y.; Bhowmik, A.; Xue, F.; Marinescu, I.; Liu, E. Evaluation of cold sprayed graphene nanoplates-Inconel 718 composite coatings. Surf. Coat. Technol. 2019, 378, 125065. [CrossRef]

76. Lek, J.Y.; Bhowmik, A.; Tan, A.W.-Y.; Sun, W.; Song, X.; Zhai, W.; Buenconsejo, P.J.; Li, F.; Liu, E.; Lam, Y.M.; et al. Understanding the microstructural evolution of cold sprayed Ti-6Al-4V coatings on Ti-6Al-4V substrates. Appl. Surf. Sci. 2018, 459, 492-504. [CrossRef]

77. Sun, W.; Bhowmik, A.; Tan, A.W.Y.; Xue, F.; Marinescu, I.; Li, F.; Liu, E. Strategy of incorporating Ni-based braze alloy in cold sprayed Inconel 718 coating. Surf. Coat. Technol. 2019, 358, 1006-1012. [CrossRef]

78. Sun, W.; Tan, A.W.Y.; Khun, N.W.; Marinescu, I.; Liu, E. Effect of substrate surface condition on fatigue behavior of cold sprayed Ti6Al4V coatings. Surf. Coat. Technol. 2017, 320, 452-457. [CrossRef]

79. Ion, J. Laser Processing of Engineering Materials: Principles, Procedure and Industrial Application; Elsevier: Amsterdam, The Netherlands, 2005.

80. Khun, N.W.; Tan, A.W.Y.; Sun, W.; Liu, E. Effects of Nd: YAG Laser Surface Treatment on Tribological Properties of Cold-Sprayed Ti-6Al-4V Coatings Tested against 100Cr6 Steel under Dry Condition. Tribol. Trans. 2019, 62, 391-402. [CrossRef]

81. Astarita, A.; Genna, S.; Leone, C.; Minutolo, F.M.C.; Rubino, F.; Squillace, A. Study of the Laser Remelting of a Cold Sprayed Titanium Layer. Procedia CIRP 2015, 33, 452-457. [CrossRef]

82. Rubino, F.; Astarita, A.; Carlone, P.; Genna, S.; Leone, C.; Memola Capece Minutolo, F.; Squillace, A. Selective Laser Post-Treatment on Titanium Cold Spray Coatings. Mater. Manuf. Process. 2015, 31, 1500-1506. [CrossRef]

83. Marrocco, T.; Hussain, T.; McCartney, D.G.; Shipway, P.H. Corrosion Performance of Laser Posttreated Cold Sprayed Titanium Coatings. J. Therm. Spray Technol. 2011, 20, 909-917. [CrossRef]

84. Poza, P.; Múnez, C.J.; Garrido-Maneiro, M.A.; Vezzù, S.; Rech, S.; Trentin, A. Mechanical properties of Inconel 625 cold-sprayed coatings after laser remelting. Depth sensing indentation analysis. Surf. Coat. Technol. 2014, 243, 51-57. [CrossRef]

85. Jing, Z.; Dejun, K. Effect of Laser Remelting on Friction-Wear Behaviors of Cold Sprayed Al Coatings in 3.5\% $\mathrm{NaCl}$ Solution. Materials 2018, 11, 283.

86. Kang, N.; Verdy, C.; Coddet, P.; Xie, Y.; Fu, Y.; Liao, H.; Coddet, C. Effects of laser remelting process on the microstructure, roughness and microhardness of in-situ cold sprayed hypoeutectic Al-Si coating. Surf. Coat. Technol. 2017, 318, 355-359. [CrossRef]

87. Kim, D.; Chang, J.-H.; Park, J.; Pak, J.J. Formation and behavior of Kirkendall voids within intermetallic layers of solder joints. J. Mater. Sci. Mater. Electron. 2011, 22, 703-716. [CrossRef]

88. Tariq, N.H.; Gyansah, L.; Qiu, X.; Du, H.; Wang, J.Q.; Feng, B.; Yan, D.S.; Xiong, T.Y. Thermo-mechanical post-treatment: A strategic approach to improve microstructure and mechanical properties of cold spray additively manufactured composites. Mater. Des. 2018, 156, 287-299. [CrossRef] 
89. Qiu, X.; Tariq, N.U.H.; Qi, L.; Zan, Y.-N.; Wang, Y.-J.; Wang, J.-Q.; Du, H.; Xiong, T.-Y. In-situ Sip/A380 alloy nano/micro composite formation through cold spray additive manufacturing and subsequent hot rolling treatment: Microstructure and mechanical properties. J. Alloys Compd. 2019, 780, 597-606. [CrossRef]

90. Tariq, N.U.H.; Gyansah, L.; Qiu, X.; Jia, C.; Awais, H.B.; Zheng, C.; Du, H.; Wang, J.; Xiong, T. Achieving strength-ductility synergy in cold spray additively manufactured $\mathrm{Al} / \mathrm{B} 4 \mathrm{C}$ composites through a hybrid post-deposition treatment. J. Mater. Sci. Technol. 2019, 35, 1053-1063. [CrossRef]

91. Courbon, C.; Sova, A.; Valiorgue, F.; Pascal, H.; Sijobert, J.; Kermouche, G.; Bertrand, P.; Rech, J. Near surface transformations of stainless steel cold spray and laser cladding deposits after turning and ball-burnishing. Surf. Coat. Technol. 2019, 371, 235-244. [CrossRef]

92. Chomienne, V.; Valiorgue, F.; Rech, J.; Verdu, C. Influence of ball burnishing on residual stress profile of a 15-5PH stainless steel. CIRP J. Manuf. Sci. Technol. 2016, 13, 90-96. [CrossRef]

93. Beladi, H.; Kelly, G.L.; Hodgson, P.D. Ultrafine grained structure formation in steels using dynamic strain induced transformation processing. Int. Mater. Rev. 2007, 52, 14-28. [CrossRef]

94. Sova, A.; Courbon, C.; Valiorgue, F.; Rech, J.; Bertrand, P. Effect of Turning and Ball Burnishing on the Microstructure and Residual Stress Distribution in Stainless Steel Cold Spray Deposits. J. Therm. Spray Technol. 2017, 26, 1922-1934. [CrossRef]

95. Chen, C.; Xie, Y.; Yan, X.; Yin, S.; Fukanuma, H.; Huang, R.; Zhao, R.; Wang, J.; Ren, Z.; Liu, M.; et al. Effect of hot isostatic pressing (HIP) on microstructure and mechanical properties of Ti6Al4V alloy fabricated by cold spray additive manufacturing. Addit. Manuf. 2019, 27, 595-605. [CrossRef]

96. Petrovskiy, P.; Sova, A.; Doubenskaia, M.; Smurov, I. Influence of hot isostatic pressing on structure and properties of titanium cold-spray deposits. Int. J. Adv. Manuf. Technol. 2019, 102, 819-827. [CrossRef]

(C) 2020 by the authors. Licensee MDPI, Basel, Switzerland. This article is an open access article distributed under the terms and conditions of the Creative Commons Attribution (CC BY) license (http://creativecommons.org/licenses/by/4.0/). 